\title{
Intrinsic Connections of Macaque Striate Cortex: Axonal Projections of Cells Outside Lamina $4 \mathrm{C}^{1}$
}

\author{
GARY G. BLASDEL, ${ }^{\star 2}$ JENNIFER S. LUND,‡ AND DAVID FITZPATRICK§ \\ Departments of ${ }^{\star}$ Ophthalmology and $\ddagger$ Psychiatry, School of Medicine, University of Pittsburgh, Pittsburgh, Pennsylvania 15261, and \\ $\S$ Department of Anatomy, Dukc University, Durham, North Carolina 27710
}

\begin{abstract}
We have exploited a technique for making small injections of horseradish peroxidase into single cortical laminae in order to study axonal projections in macaque striate cortex. In the preceding paper (Fitzpatrick, D., J. S. Lund, and G. G. Blasdel (1985) J. Neurosci. 5: 3329-3349) we examined the projections of cells in lamina $4 \mathrm{C}$-cells that receive most of their input from the lateral geniculate nucleus. The present paper deals with the projections of neurons that lie outside of lamina 4C. Among our findings are several projections that previously had not been described in the monkey. These include: (1) a strong and precise (point-to-point) projection from lamina $4 B$ to lamina $2 / 3 A,(2)$ a reciprocal projection from $2 / 3 A$ back to $4 B,(3)$ a definite projection from lamina $4 B$ to $5 B$, as well as (4) a prominent input to lamina 6 from 5B. In many cases, we find it possible to trace the flow of visual information through several "circuits" in striate cortex that have, as their output, projections to extrastriate cortex or to the brainstem. Our results offer additional insights in this regard since we are able, in many cases, to compare the lateral spreads of particular projections. These vary and can be separated into at least three categories: (1) those that terminate in a precise, point-to-point, fashion, $(2)$ those that spread widely, and (3) those that terminate in a laterally periodic fashion. In several cases we find evidence for a correlation between specific patterns of projection and known physiological differences between the topographies of laminae that are connected. In cases where two laminae possess similar topographies (for example, where both contain orderly maps for orientation) their interconnections appear precise, with little diffuse spread. In cases where two laminae are characterized by strikingly different topographies (where, for example, one contains an orderly map for orientation and the other a precise map for retinotopic position, but no specificity for orientation), the connections appear more diffuse.
\end{abstract}

Received February 19, 1985; Revised May 22, 1985;

Accepted May 22, 1985

\footnotetext{
${ }^{1}$ This work was supported by National Institutes of Health Grants EY03321 and EY05282 to J. S. L. and G. G. B. and Grant EY05543 to D. F. We thank Kathryn Cowart, Kathy Ludden, Tom Harper, and Suzanne Holbach for technical assistance, and Roberta Erickson for help in preparing the manuscript.

${ }^{2}$ To whom correspondence should be addressed at, his present address: Department of Physiology, University of Calgary, Calgary, Alberta Canada T2N-1M4.
}

The orderliness of striate cortex is particularly apparent in the monkey (Hubel and Wiesel, 1968, 1974, 1977; Lund, 1973, 1980; Tigges et al., 1981; Livingstone and Hubel, 1984a, b). Between lamina $4 \mathrm{C}$, where most geniculate afferents terminate, and the laminae containing neurons that project outside of striate cortex, it is possible to discern at least one (and frequently several) discrete step in the transfer of visual information. These steps are apparent anatomically, from the stratification of particular cell groups as well as from patterns of interlaminar projection (Lund, 1973; Lund and Boothe, 1975). They are also reflected physiologically, both by increases in response latency (Mitzdorf and Singer, 1979; Bullier and Henry, 1980) and by the response properties of isolated neurons (Hubel and Wiesel, 1968, 1974, 1977; Dow, 1974; Dow et al., 1981; Michael, 1978; Schiller et al., 1976; Blasdel and Fitzpatrick, 1984; Livingstone and Hubel, 1984a). Although many features of the interlaminar projections that produce these steps are understood generally, cerlain details are missing. One would like to know, for example, whether the interlaminar flow of information proceeds in a radially precise manner-one that is point-to-point--or whether it diverges. If it diverges, does it spread symmetrically about a particular projection axis, or is the distribution asymmetric? And how smooth is the distribution? Does it occur evenly, in a manner that would encourage the further use of linear techniques for analyzing cortical function (Movshon et al., 1978; De Valois et al., 1982; Pollen and Ronner, 1983), or is it discontinuous and patchy?

In the preceding paper (Fitzpatrick et al., 1985) we described the projections of neurons in lamina $4 \mathrm{C}$, the lamina where most geniculate afferents terminate. On the basis of these projections we found evidence for structural subdivisions within striate cortex that previously had not been deduced. In addition, we showed that projections out of these subdivisions-to laminae $3 B / 4 A, 4 B, 5 A$, and 6 , respectively-show differing amounts of lateral spread and asymmetry. Given the detailed knowledge that we currently have concerning the response properties of cells occupying the subdivisions of lamina 4C (Hubel and Wiesel, 1977; Michael, 1978; Mitzdorf and Singer, 1979; Blasdel and Fitzpatrick, 1984; Parker and Hawken, 1984), precise information about their anatomical projections allows us to deduce spatial constraints for the visual information that reaches cells lying postsynaptic.

In the present paper we carry this analysis one step further by examining the projections of neurons that receive their input from cells in lamina 4C. Since we know less about the physiological properties of these cells than we do about cells in lamina $4 C$, the spatial constraints that we can deduce are necessarily more limited. A number of insights are still possible, however. As in the previous paper (Fitzpatrick et al., 1985), our results are based both on the orthograde and on the retrograde transport of horseradish peroxidase (HRP). These results are organized into six parts. In the first 

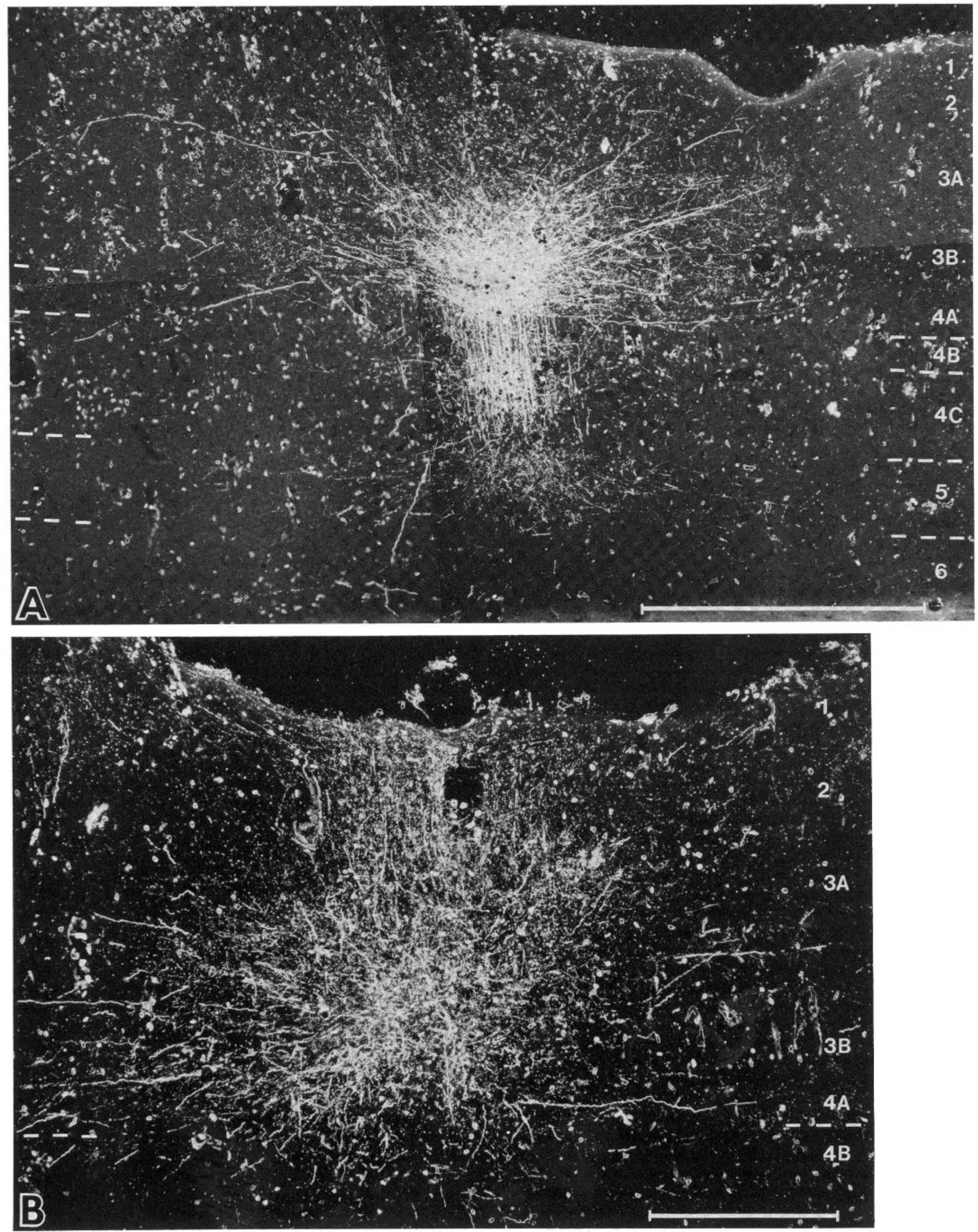

Figure 1. Darkfield photomicrographs of fiber labeling after an injection into lamina 3B/4A. A broad, fan-shaped arbor $(A)$ reaches laterally for at least 750 $\mu \mathrm{m}$ within lamina $2 / 3 \mathrm{~A}$, and a vertically oriented projection $(B)$ terminates in lamina $2 / 3 \mathrm{~A}$ immediately over the injection site. Due to the oblique angle of this section, with respect to the projection axis, these two projections do not appear in the same section. The scale bar in $A$ represents $500 \mu \mathrm{m}$; that in $B$ represents $250 \mu \mathrm{m}$. 


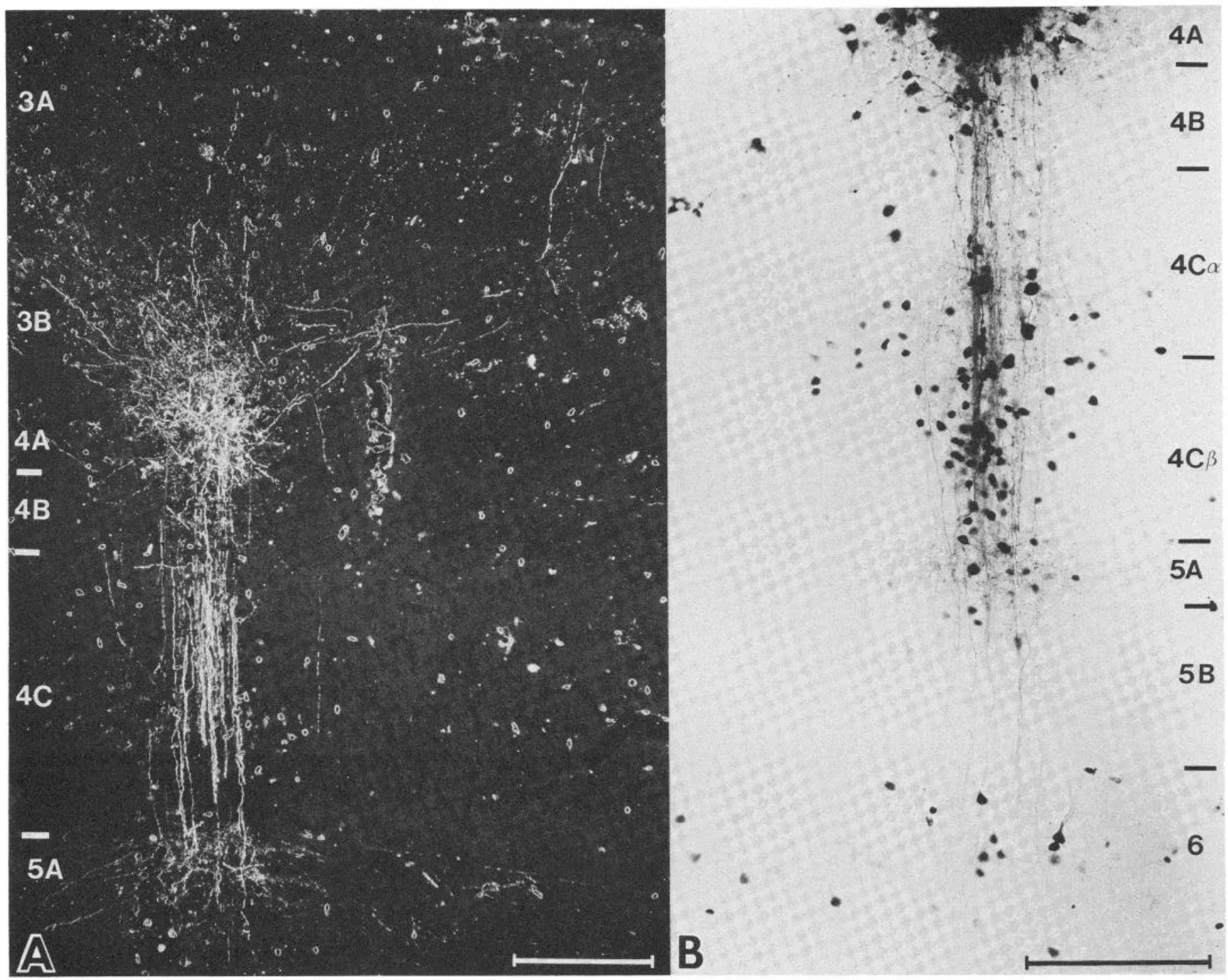

Figure 2. Microinjection into lamina 3B/4A. In the darkfield photomicrograph on the left $(A)$, one can observe coarse fibers that spread upward and to the right of the injection. Below the injection it is also possible to see that descending fibers give rise to collaterals in lamina 5 . In the brightfield photomicrograph on the right $(B)$, which is taken from an adjacent section but from the same injection site, one sees a cluster of retrogradely labeled somata in lamina $5 \mathrm{~A}$, as well as a cluster of beaded terminals. Fibers can also be observed descending through layer 6 to the white matter. Scale bars $(A$ and $B)=200 \mu \mathrm{m}$.

three we deal with the projections of neurons that receive a prominent input from lamina $4 \mathrm{C}$-those residing in layers $3 B / 4 \mathrm{~A}, 4 \mathrm{~B}$, and $5 A$ (Lund, 1973; Lund and Boothe, 1975). We analyze laminae $2 / 3 A$ and $5 B$ separately in the fourth and fifth sections since these laminae: (1) must rely on cells in other layers for (indirect) $4 \mathrm{C}$ input, and (2) are major sources of efferent projections. Lamina 6 is discussed last in its principal role of providing feedback to thalamorecipient laminae of striate cortex, as well as to the lateral geniculate nucleus (LGN). Some of these results have been reported briefly (Blasdel et al., 1983; Lund et al., 1983).

\section{Materials and Methods}

The methods used in this study are fully described in the preceding paper (Fitzpatrick et al., 1985). Briefly, they entail the filling of micropipettes with a $20 \%$ solution of HRP (Boehringer) in saline, breaking their tips to 5 to $10 \mu \mathrm{m}$, and advancing them, at an angle, to various depths within the striate cortex of an anesthetized, adult monkey (four Macaca fascicularis, two Macaca nemestrina). Depositions of HRP were accomplished by passing anodal currents $(0.5$ to $1.0 \mu \mathrm{A})$ for 5 to $10 \mathrm{~min}$. Following this, each pipette was withdrawn and the procedure was repeated elsewhere. In some cases, recordings were used to assess the depths of desired laminar targets. Many of the animals used in this study also participated in a previous physiological analysis of lamina 4C (Blasdel and Fitzpatrick, 1984), an analysis that helped with the accurate placement of some of the injections reported here.

\section{Results}

Lamina $3 B / 4 A$. Laminae $3 B$ and $4 A$ receive two major sources of afferent input: one from cells in the parvocellular laminae of the LGN, which project to lamina 4A (Hubel and Wiesel, 1972; Hendrickson et al., 1978), and another from cells in lamina $4 C \beta$ which project both to $4 \mathrm{~A}$ and to $3 \mathrm{~B}$ (Fitzpatrick et al., 1985). This region also receives a less prominent input from lamina $4 \mathrm{C} \alpha$ and possibly from the intercalated LGN laminae as well. For squirrel monkeys, at least, the intercalated laminae are known to project in a patchy fashion to the cytochrome oxidase "blobs" in layer 3 (Fitzpatrick et al., 1983).

On the basis of orthograde transport, one can discern two projections out of lamina $3 B / 4 A$ - a major one to 2/3A (Fig. 1) and a lighter one to $5 \mathrm{~A}$ (Fig. 2). The larger projection, to lamina $2 / 3 \mathrm{~A}$, consists of two components: a broad, fan-shaped one that reaches $750 \mu \mathrm{m}$ laterally (Fig. 1A) and a more highly focused, vertical one (Fig. 1B). Within lamina $3 \mathrm{~B} / 4 \mathrm{~A}$ itself, occasional coarse axon trunks produce lateral and asymmetric terminal arbors (Figs. $2 A$ and 3 ). Sometimes a narrow band of beaded fibers distributes laterally in $4 \mathrm{~A}$ alone; but 



Figure 3. Fiber projections that result from two separate HRP injections into lamina 3B/4A. Coarse axon trunks spread laterally from each injection. Scale bar (for $A$ and $B$ ) $=250 \mu \mathrm{m}$. 


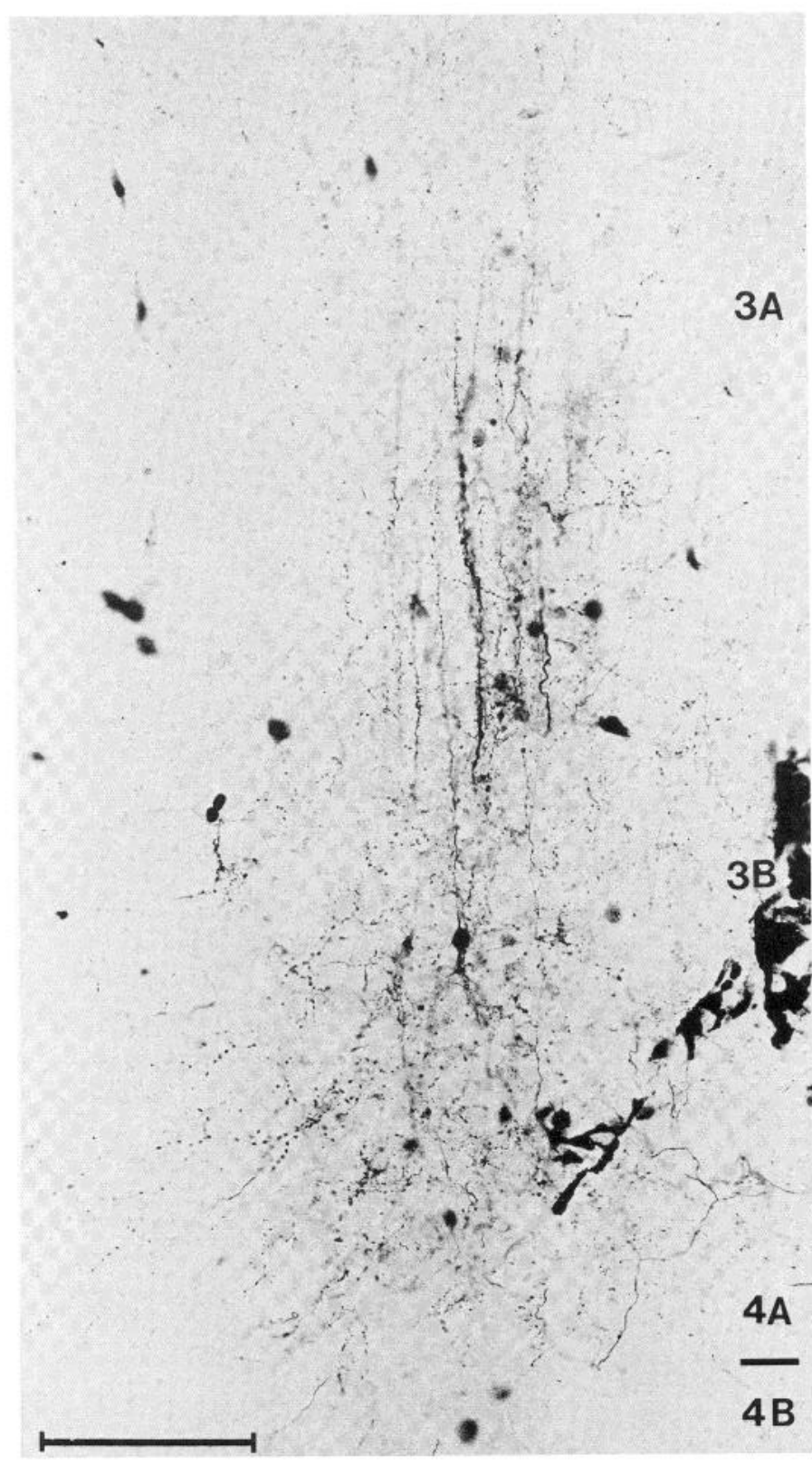

Figure 4. In this brightfield photomicrograph, a field of swirling beaded fibers can be observed approximately $150 \mu \mathrm{m}$ to one side of the center of an injection in lamina 3B/4A. Fibers such as these are characteristic of smooth dendritic neurons (perhaps inhibitory). Scale bar $=100 \mu \mathrm{m}$.

more often the fibers extend into $3 \mathrm{~B}$ as well. These arise, presumably, from local, smooth dendritic neurons that lie close to the injection site (Fig. 4). Below the injection, axon trunks descend as a prominent column through laminae 5 and 6 (Fig. 2) and into the white matter. The descending fibers occasionally give rise to collaterals that emerge just below the injection site and run for long distances laterally in lamina 4B (Fig. 3B). Some rise, however, and add to the fan of fibers in layer $2 / 3 \mathrm{~A}$. In addition to the relatively discrete projection to $5 \mathrm{~A}$, described above, one can occasionally observe sparse and more laterally spreading collaterals in lamina 5B that spread as far as $550 \mu \mathrm{m}$ lateral to the radial projection axis (Figs. $1 A$ and $2 A$ ). In lamina 6 one can see a light, orthogradely filled projection from beaded axons that terminate beneath the injection site. The patterns of orthograde label, produced by injections into lamina $3 \mathrm{~B} / 4 \mathrm{~A}$, are summarized in Figure 5.
The projections from lamina $3 \mathrm{~B} / 4 \mathrm{~A}$ to $2 / 3 \mathrm{~A}$ and to $5 \mathrm{~A}$ are apparent with retrograde transport as well. Microinjections into lamina 2/3A lead to the scattered labeling of neurons in lamina 3B/4A (Fig. 6), a result that reinforces the observation, described above, that the spreading component of the 2/3A projection derives from lamina $3 \mathrm{~B} / 4 \mathrm{~A}$. There are, however, no indications of clustered somata in $3 \mathrm{~B} / 4 \mathrm{~A}$ - as one might predict were the focused component of the $2 / 3 A$ projection to derive from lamina $3 B / 4 A$ as well. Such clustering is apparent only in lamina $4 B$, directly under the injection site. Accordingly, it appears that the wide ranging, fan-shaped component of the projection to lamina 2/3A (seen following injections into $3 B / 4 A$ ) derives from neurons in lamina $3 B / 4 A$, whereas the more discrete and vertically oriented component derives mostly from neurons in lamina 4B that have been labeled inadvertently (Figs. $1 B$ and 2).

The projection from lamina $3 B / 4 A$ to $5 \mathrm{~A}$ is supported in the retrograde direction by injections into lamina 5 . Each of these typically produces a column of heavily labeled somata that passes radially through laminae $3 B / 4 A$ and 2 (see Fig. $16 B$ ). Although the injection shown in Figure $16 B$ impinges on lower $4 C \beta$ as well, we believe that the neurons in $3 B / 4 A$ were filled retrogradely from $5 A$ since these cells do not fill from injections that are confined to lamina 4C $\beta$ (see Fig. 11 of Fitzpatrick et al., 1985). Retrograde transport from microinjections in lamina 6 to a few widely scattered neurons in laminae 2/3A and 4A (see Fig. 20) provides additional support for the sparse projection from lamina $3 B / 4 A$ to 6 , described above.

Lamina $4 B$. Lamina $4 B$ receives most of its intrinsic input from neurons in lamina 4C $\alpha$ (Lund, 1973; Fitzpatrick et al., 1985). Microinjections into lamina 4B result in a narrowly focused and quite heavy projection that terminates in lamina $2 / 3 A$ (Fig. $8 A$ ). Fibers making this projection follow a narrow column of heavy orthograde label that is little wider than the injection site itself. Arising out of this column, a few coarse fibers fan upward and away from the radial projection axis, and travel as far as $375 \mu \mathrm{m}$ laterally in lamina 2/3A. Within lamina $4 \mathrm{~B}$ there is a heavy band of efferent axons that stretches laterally from the injection site. This band, which reaches for 3 to 4 $\mathrm{mm}$, is punctuated by periodic accumulations of denser terminal fibers that appear at 375- to $400-\mu \mathrm{m}$ intervals (Fig. 7). A few fibers rise radially out of the heavily labeled accumulations to form light terminal fields in lamina $2 / 3 \mathrm{~A}$ (Fig. $8 B$ ) - a tendency that produces several patches in lamina $2 / 3 A$ that lie in register with deeper patches in layer $4 \mathrm{~B}$.

Beneath the injection site, axon trunks descend vertically along the radial axis and give rise to a heavy focus of terminals in lamina 5 as well as to a collection of sparser, coarse fibers that extend laterally as far as 800 to $1500 \mu \mathrm{m}$ (Figs. 7 and 9B). Descending axon trunks continue vertically through lamina 6 and then turn laterally as they pass out of lamina 6 and into the white matter (Fig. $9 B$ ). Within lamina 6 , and imbedded within the column of axons, there is a light field of terminals (Fig. 10). The fiber and cell labeling that result from microinjections in lamina 4B appear summarized in Figure 11

Microinjections into lamina 2/3A provide retrograde evidence for the focused projections of $4 \mathrm{~B}$ neurons into lamina $2 / 3 \mathrm{~A}$ by revealing tight clusters of labeled neurons in lamina $4 B$ (Fig. 6). Retrograde evidence for the lateral projections within layer $4 \mathrm{~B}$ may be derived from injections in lamina $4 B$ that show labeled pyramidal and spiny stellate cells lateral to the injection site. These are especially prominent within the patchy zones that receive orthograde label (as discussed previously by Rockland and Lund, 1983). In agreement with the rather wide ranging projections that we observed for efferent projections from lamina $4 \mathrm{~B}$ to 5 , injections into lamina 5 (see Figs. $16 B$ and 17) produce a few retrogradely labeled cells in $4 B$, but no tight clusters. Similarly, injections into lamina 6 produce only a few retrogradely labeled cells in lamina 4B (see summary diagram in Fig. 20).

Lamina $5 A$. Lamina $5 \mathrm{~A}$ consists of a thin band of neurons that 


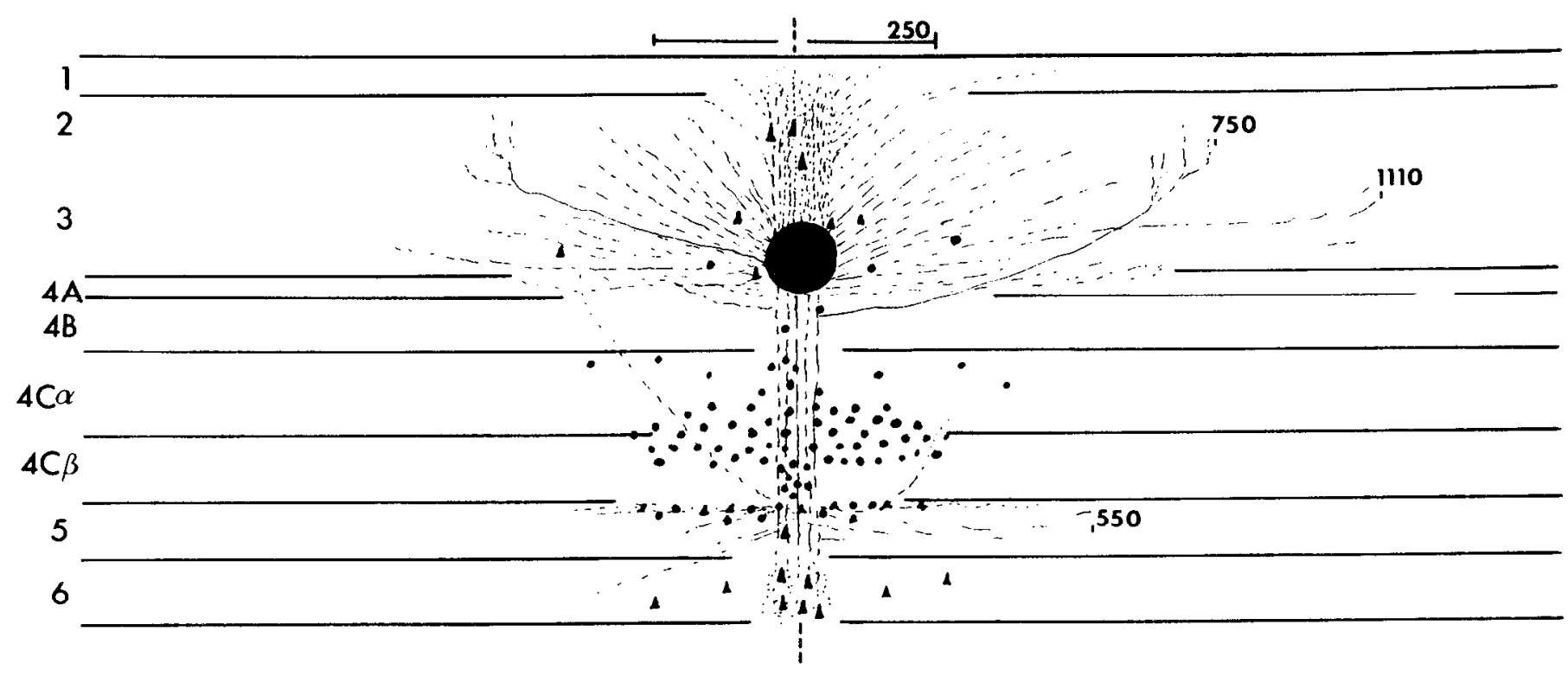

Figure 5. Diagram summarizing results of retrograde and orthograde labeling after HRP injections into lamina 3B/4A. The lateral spread is indicated (in micrometers) for processes that spread farthest away from the radial projection axis. This axis is indicated by dasined line segments appearing above and beluw the cortex.

lies immediately under lamina $4 \mathrm{C} \beta$ and receives prominent inputs from laminae $4 \mathrm{C} \alpha, 4 \mathrm{~B}$ (Fig. 12), 3B/4A (Fig. 2), and 2/3A (Fig. 6), as well as a lighter input from lamina 6 (see Fig. 18). Unlike the cells of lamina 5B, which project subcortically, the neurons of lamina $5 \mathrm{~A}$ do not project outside of striate cortex. Instead they feed back onto lamina $2 / 3 \mathrm{~A}$ and contribute heavier projections to laminae $3 \mathrm{~B} / 4 \mathrm{~A}$ and $4 \mathrm{C}$-laminae that supply them with afferent input (see Fig. 16A). As described below, injections biased toward larmina $5 B$ (see Figs. 14,15 , and $17 A$ ) yield rising trunks that pass vertically, in a narrow column that is about the same width as the injection site, through laminae $4 \mathrm{C}$ and $4 \mathrm{~B}$ into laminae $2 / 3 \mathrm{~A}$ and 1 where they form a prominent fan of fibers that spreads about the radial axis (see Fig. 15). When the injection is centered in lamina 5A, this efferent projection assumes a columnar form (200 $\mu \mathrm{m}$ wide following a 100 $\mu \mathrm{m}$-wide injection) and displays a much smaller spread of its terminal fibers ( $400 \mu \mathrm{m}$ in width-see Fig. $16 \mathrm{~A}$ and summary diagram in Fig. 17A). From a comparison between superficial injections, centered on lamina $5 \mathrm{~A}$, and injections filling the depth of lamina 5 , one discerns a trend whereby lamina $5 \mathrm{~A}$ provides a focused contribution to laminae $2 / 3 \mathrm{~A}$ and $3 \mathrm{~B} / 4 \mathrm{~A}$, and $5 \mathrm{~B}$ contributes more to the broadly spreading efferents in laminae $2 / 3 \mathrm{~A}$ and 1 .

It is possible to produce a prominent patch of retrogradely labeled neurons in lamina $5 \mathrm{~A}$ by making an injection into $3 \mathrm{~B} / 4 \mathrm{~A}$ (Figs. $2 \mathrm{~B}$ and 6 ) or into lamina $4 \mathrm{~B}$ (Fig. 9A). If lamina $2 / 3 \mathrm{~A}$ is injected, one observes (Fig. 6) a column of labeled neurons that lies under the injection site and that extends all the way through lamina 5 . There are also a number of more scattered cells in lamina 5, that extend for some distance away from the radial projection axis.

Lamina 2/3A: This zone receives little or no direct input from lamina 4C; and, although it receives some input from the LGN (to the cytochrome oxidase blobs-Fitzpatrick et al., 1983; Livingstone and Hubel, 1984a), most of its intrinsic input comes from other striate laminae that do receive a direct input from lamina $4 \mathrm{C}$. As discussed in the preceding sections, lamina 2/3A receives major inputs from lamina $3 \mathrm{~B} / 4 \mathrm{~A}$ (terminating with diffuse, broadly spreading arbors) and from lamina $4 \mathrm{~B}$ (which provides a more focused, point to-point projection). In addition to these primary inputs, lamina $2 / 3 \mathrm{~A}$ receives a focused input from lamina $5 \mathrm{~A}$ and a diffuse one from $5 \mathrm{~B}$. Inputs from lamina 6 appear focused, but light.

Following injections into lamina $2 / 3 \mathrm{~A}$, laterally traveling fibers establish diffuse local arbors and distant patchy terminal fields. Clusters of neurons, many of which are pyramidal, label over wide distances and coincide with patches of orthoyradely transporled label at the same level as the injection site. Similar patches have been described previously, following much larger injections (sæe Rockland and Lund, 1983); however, it is intriguing that, with the smaller injections used to achieve the present material, these projeclions sometimes appear asymmetric, traveling only to one side of the injection site. The tendency is even more apparent in the tangential sections of Livingstone and Hubel (1984b), that were cut from lamina 2/3A following similarly discrete microinjections.

Below the injection, axon trunks descend vertically, along the radial projection axis, and give off fine collaterals in lamina 4B (Figs. 6 and 12). This projection seems to be just as precise when viewed in the retrograde direction; microinjections into $4 \mathrm{~B}$ cause patches of neurons to be labeled in lamina $2 / 3 A$, immediately above each injection site (Fig. 8A).

Lamina $2 / 3 A$ does not project to lamina $4 C$, but below $4 C$ the axons that descend from injections into $2 / 3 \mathrm{~A}$ yield prominent and widely spreading (up to $1 \mathrm{~mm}$ ) collaterals in lamina 5 (Figs. 6 and 12). These collaterals give rise to light terminal clusters that occur periodically in lamina 5 and that overlap with the projection zones of laterally dosconding axons from lamina $2 / 3 \mathrm{~A}$ above (see Fig. 13). Below the injection site, the main descending axon trunks continue vertically through lamina 6 where they give rise to a light, but tightly focused, terminal field. The descending axons then turn laterally in deep lamina 6 as they pass into the white matter (Figs. 12 and 13).

Examined in the retrograde direction, injections into lamina 5 produce clusters of labeled somata in lamina $2 / 3 \mathrm{~A}$ directly above the injection sites (as well as in laminae $3 B / 4 A$ and $4 B$, as described above-Figs. $16 B$ and 17). Lamina 6 injections (see Fig. 20) occasionally label cells in lamina $2 / 3 \mathrm{~A}$, an observation that agrees with the orthograde evidence for a light projection from this lamina into lamina 6. Although this filling could result from the inadvertent labeling of efferent axon trunks (which pass through lamina 6 on their way to extrastriate cortex), the absence of labeled somata in lamina 5 suggests that filling via descending trunks is not a major factor.

Lamina 5B. Like lamina 2/3A, lamina 5B does not receive a direct input from lamina $4 C$. It does receive a prominent input from lamina 


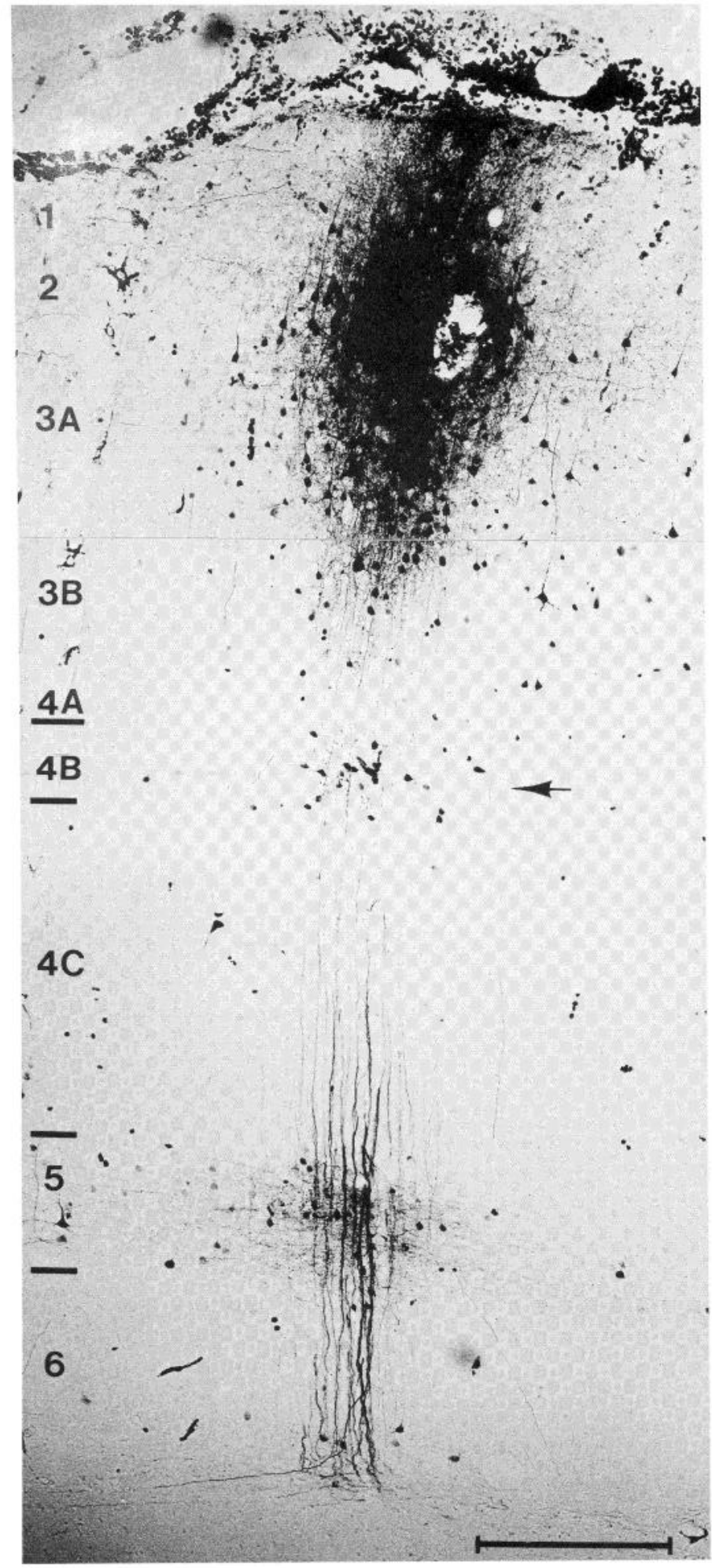

Figure 6 . Following an injection of HRP into lamina $2 / 3 \mathrm{~A}$, one can observe scattered cell labeling in $3 \mathrm{~B} / 4 \mathrm{~A}$ along with a cluster of well labeled cells in lamina 4B (arrow). Both lie directly below the injection site. Intertwined with the labeled somata in lamina $4 \mathrm{~B}$, it is also possible to see sparse terminal label. In lamina 5, one can observe descending axons along with retrogradely labeled somata. Axons passing through lamina 5 pass through lamina 6 as well and into the white matter. A few labeled cells may be observed in lamina 6 . This same section appears in Figure 12, photographed with darkfield, which makes it possible to see the wide extent of the fine axon arbors that spread in lamina 5. Scale bar $=200 \mu \mathrm{m}$.

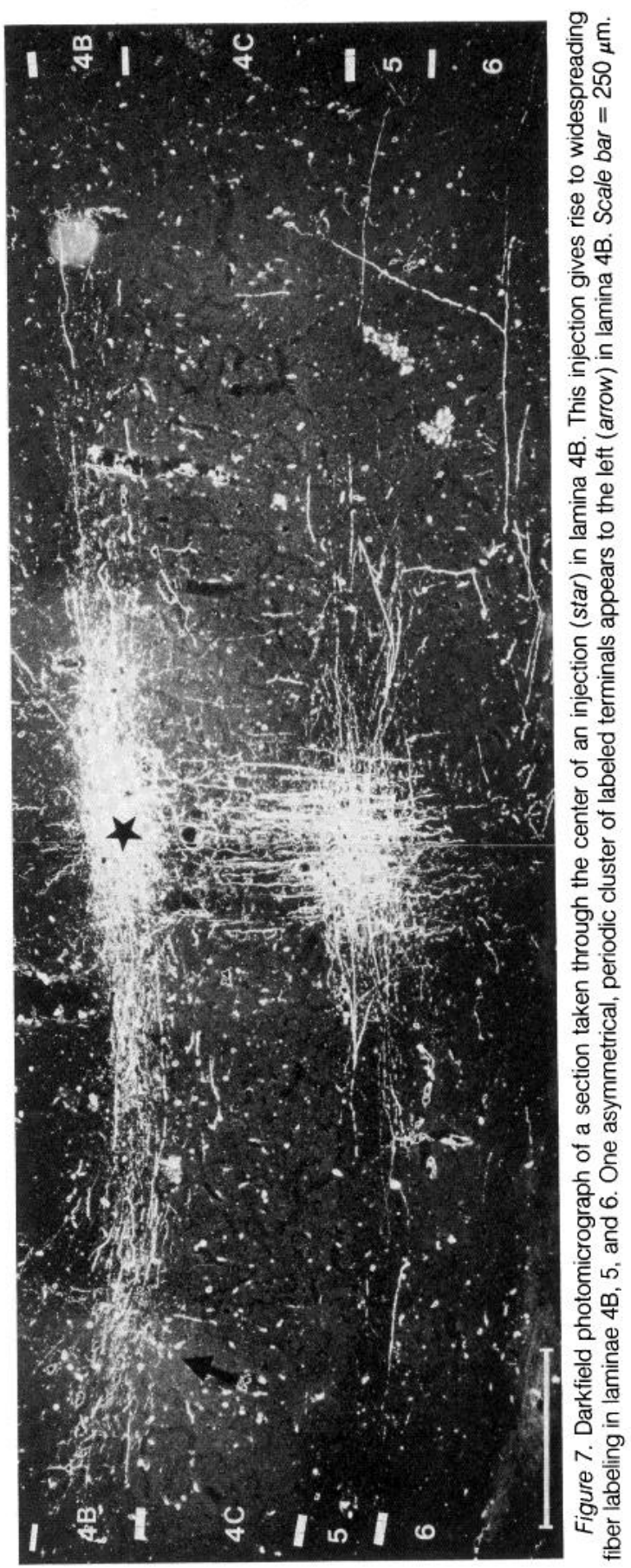



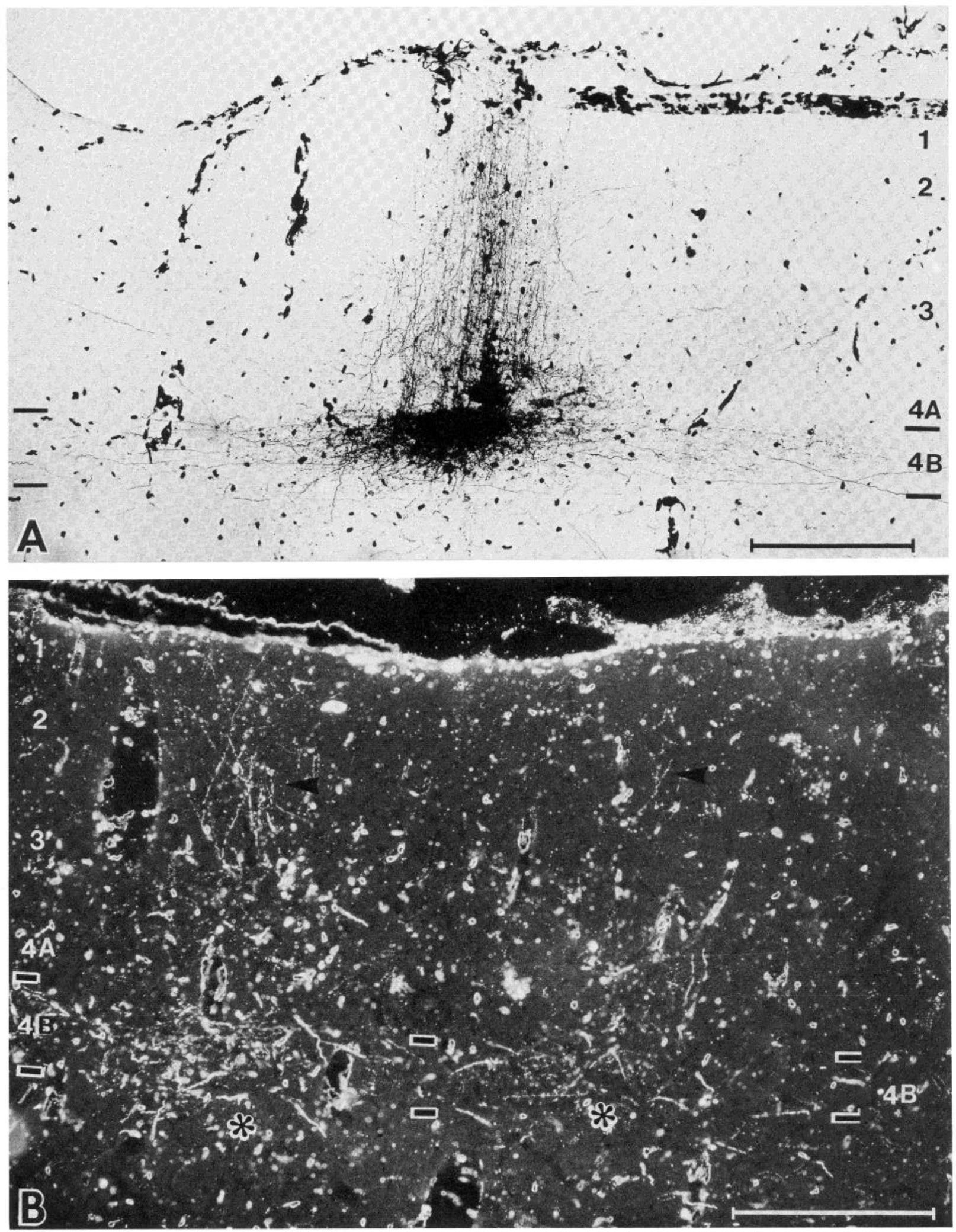

Figure 8. A, An injection in lamina $4 B$ yields a vertically rising column of fibers in lamina $2 / 3 \mathrm{~A}$. Lateral to the injection site, a few fibers can also be observed to travel outward for some distance, rising within $2 / 3 \mathrm{~A}$. Prominent fibers spread within 4B. Scale bar $=250 \mu \mathrm{m}$. B, Lateral to the 4B injection site seen in $A$, a few clusters (asterisks) of labeled terminals give rise in $4 \mathrm{~B}$ to fibers (arrowheads) that rise into lamina $2 / 3 \mathrm{~A}$. Scale bar $=250 \mu \mathrm{m}$.

$2 / 3 \mathrm{~A}$, however, both from the collateral projections described above and onto the apical dendrites of lamina 5B pyramidal neurons which arborize in 2/3A (Lund, 1973).

As noted above, injections that are large enough to fill lamina 5 (i.e., 100 to $200 \mu \mathrm{m}$ in diameter) yield axon trunks that rise in a narrow, vertical column that is about as wide as the injection site (Figs. 14, 15, and 17A). These axons rise through lamina $4 \mathrm{C}$ and $4 \mathrm{~B}$ into lamina $2 / 3 \mathrm{~A}$ where they fan into wide ranging terminal arbors 

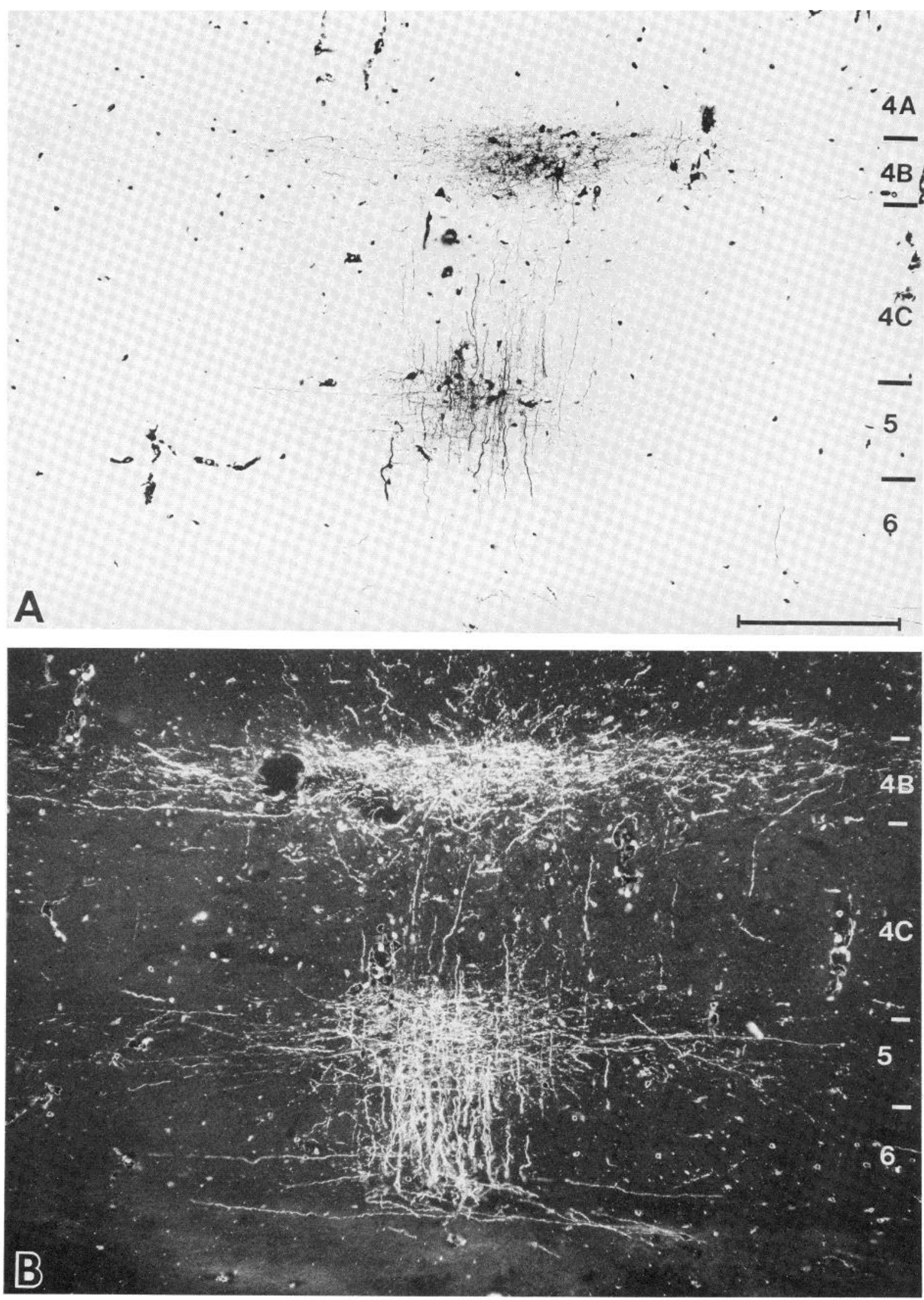

Figure 9. Brightfield $(A)$ and darkfield $(B)$ photomicrographs depicting labeling that is observed following an injection into lamina $4 \mathrm{~B}$. The brightfield photograph shows the pattern of retrograde cell labeling that may be observed in lamina 5A following an injection of HRP into lamina 4B; the darkfield photograph reveals the extent of arborizing fibers in laminae $4 \mathrm{~B}$ and 5 . Because this section is cut obliquely to the projection axis, some of the cell groups that label after $4 \mathrm{~B}$ injections (see Fig. 11) are not evident. Scale bar (for $A$ and $B$ ) $=250 \mu \mathrm{m}$. 


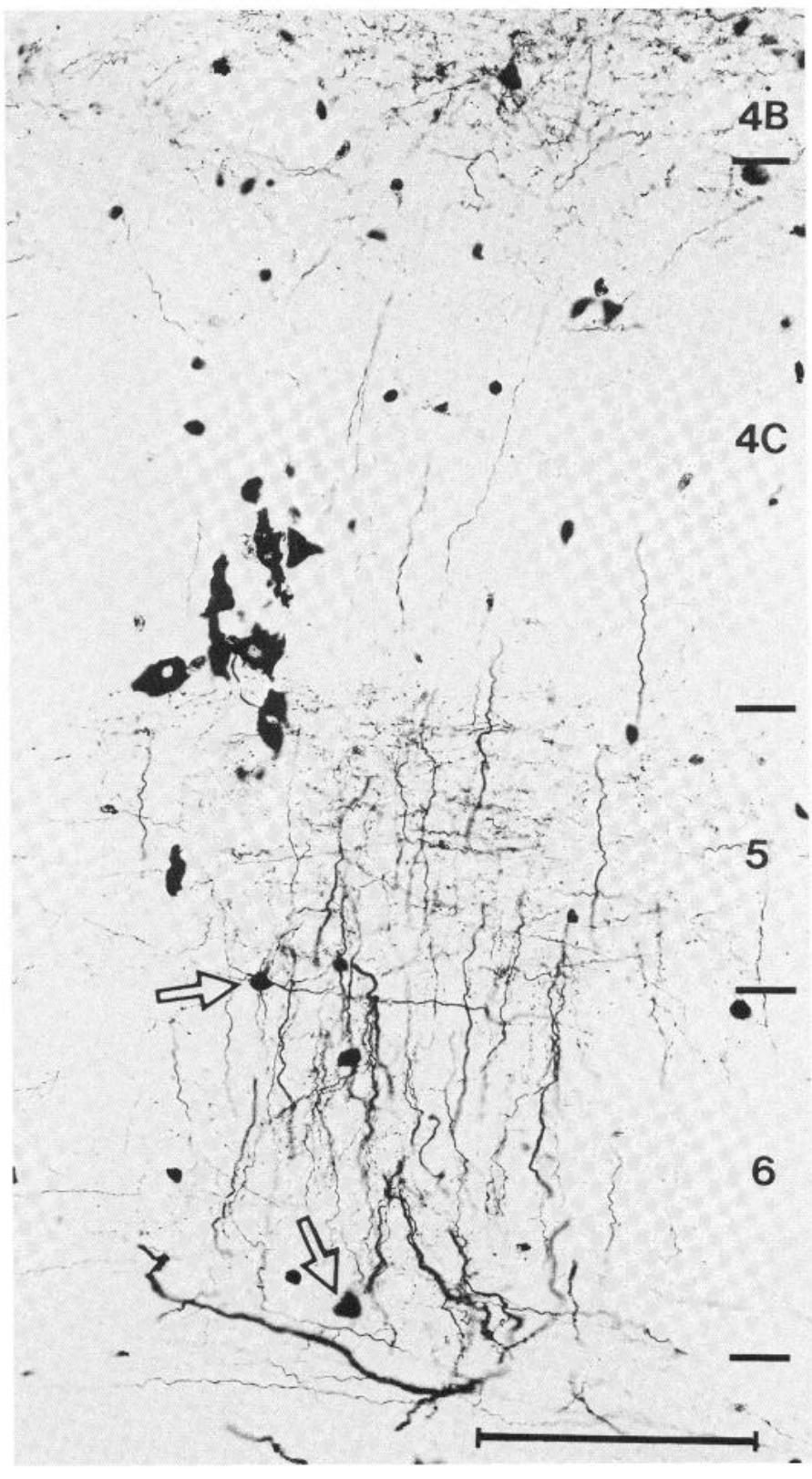

that spread 600 to $1000 \mu \mathrm{m}$ to each side of the radial projection axis (Fig. 15). Since this amount of spread is very much more than that produced by injections that are limited to lamina 5A (Figs. $16 \mathrm{~A}$ and $17 A$ ), we believe that it derives primarily from neurons in lamina $5 B$. The projection from $5 B$ to $2 / 3 A$ can also be demonstrated in the retrograde direction. Each microinjection placed in lamina 2/3A produces a dense patch of labeled layer 5 somata directly under the injection site, and also leads to the appearance of scattered cells that extend quite far from the radial axis (Fig. 13).

Layer 5 injections also reveal projections intrinsic to lamina 5 as a whole. These typically consist of a dense component of fine fibers that extend $500 \mu \mathrm{m}$ to each side, along with a sparser component of coarse fibers that may reach as far as $1000 \mu$ m laterally. In lamina 6 , coarse fibers spread $1.5 \mathrm{~mm}$ to each side of the radial projection axis and some axon trunks travel into the white matter (Figs. 14, 15, and $17 B)$. The coarse fibers that spread within lamina 6 comprise the most prominent input that we have observed for this lamina; however, the projection disperses so widely that it is difficult to be certain of the strength or the extent of terminal arborizations.

Lamina 6. The most prominent input to lamina 6 appears to come from lamina 5 . In addition to this input, described above, lamina 6 also receives light inputs from just about every other overlying lamina including $2 / 3 \mathrm{~A}, 3 \mathrm{~B} / 4 \mathrm{~A}, 4 \mathrm{~B}, 4 \mathrm{C} \alpha$, and at least the upper part of $4 \mathrm{C} \beta$. It also receives a light input from the $L G N$. Following injections into lamina 6 , a column of orthograde projections rises into lamina 2/3A (see Fig. 19A). Although this projection is narrowly focused, a few fibers still spread quite far laterally (up to $500 \mu \mathrm{m}$ ). The pattern of this projection is also evident with retrograde transport; an injection into lamina 2/3A typically produces a cluster of layer 6 neurons directly below (Fig. 6), along with occasional somata that are offset from the radial projection axis.

Lamina 3B receives a light but focused input from the neurons of lamina 6 , and this input may be shown with both orthograde and retrograde transport (see Figs. 2 and 19). Whereas lamina 4A receives a heavy orthograde input from lamina 6 (with laterally spreading arbors that extend over 500 to $700 \mu \mathrm{m}$; Figs. $18 B$ and 19), lamina $4 B$ stands out as a sparsely labeled cleft (Figs. 18B and 19). In keeping with this difference, injections that hit lamina $4 A$ yield more numerous and more widely spreading somata in layer 6 than do injections that are confined to lamina 4B (compare, for example, Fig. $2 B$ with Figs. 10 and 11). The projections of lamina 6 neurons

Figure 10. Retrograde labeling of somata in lamina 6 following an HRP injection into lamina 4B. Scattered terminals are also evident in lamina 6. Scale bar $=200 \mu \mathrm{m}$.

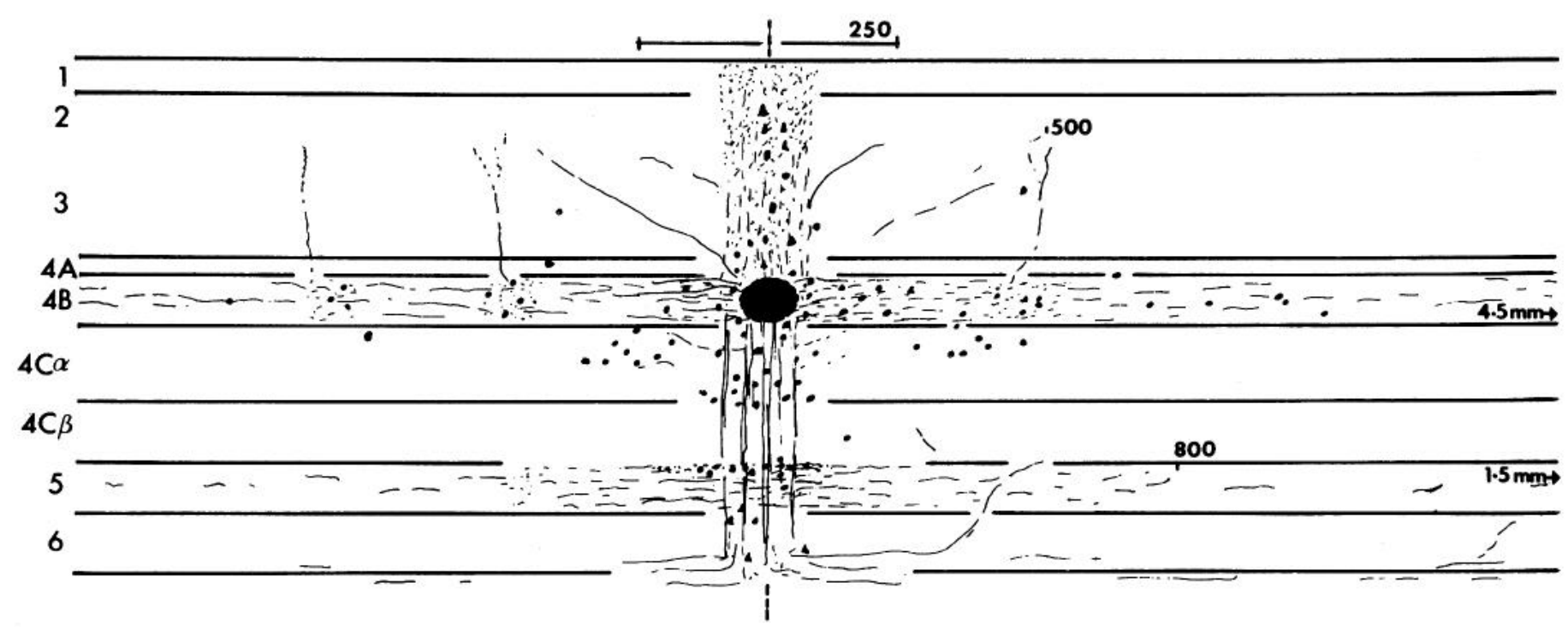

Figure 11. Summary diagram of cell and fiber labeling following an injection of HRP into lamina 4B. 


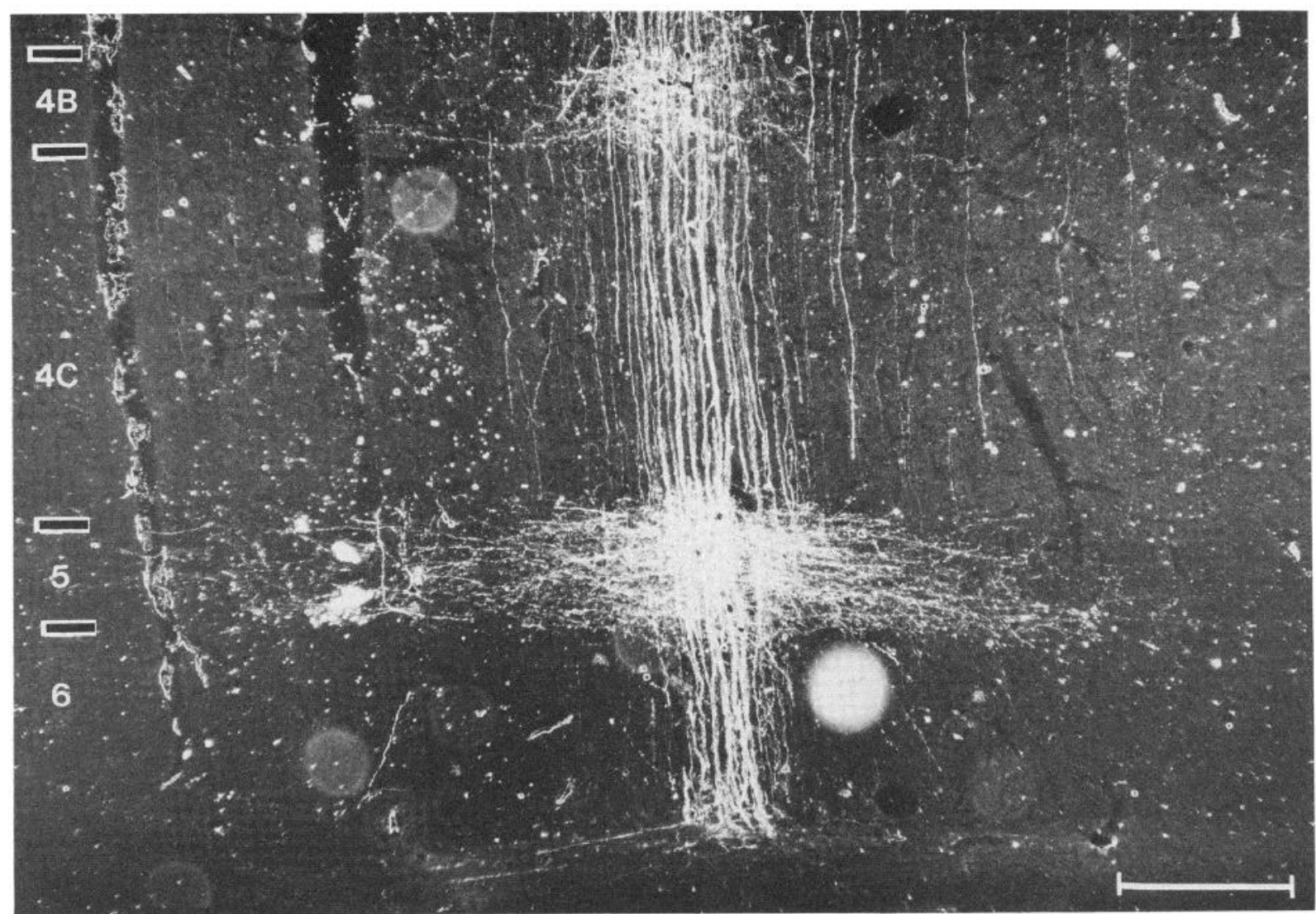

Figure 12. Darkfield photomicrograph revealing fiber labeling below an injection in lamina 2/3A. The profuse spread of this projection in lamina 5 contrasts strongly with the narrowly focused nature of the sparser terminal cluster in lamina $4 \mathrm{~B}$. The retrograde cell labeling that results from this injection is more evident in the brightfield photomicrograph of Figure 6. Scale bar $=200 \mu \mathrm{m}$.

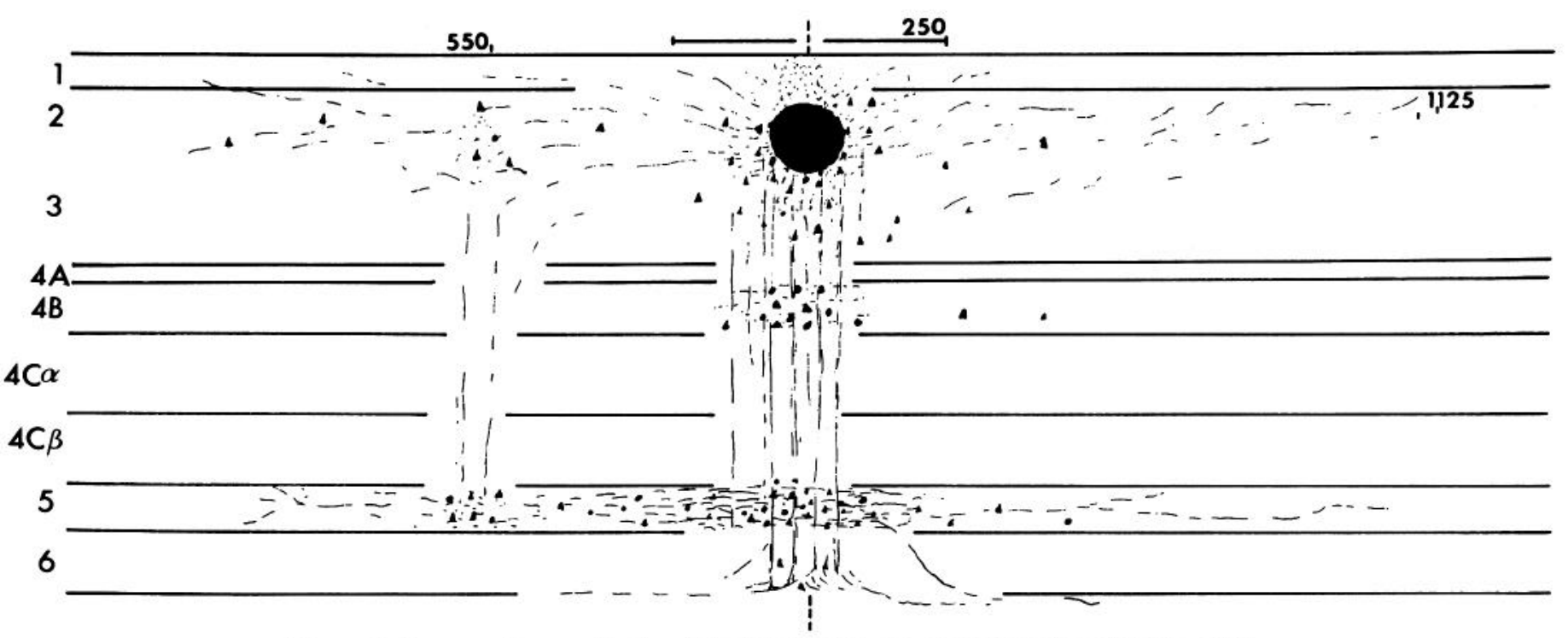

Figure 13. Summary diagram of cell and fiber labeling following an HRP injection into lamina 2/3A.

upon lamina $4 \mathrm{C}$ have been described in the preceding paper (FItzpatrick et al., 1985) and are illustrated here in Figures 18, 19, and 20.

There is a light projection from lamina 6 to lamina $5 A$, but lamina $5 B$ receives little or no input (Figs. $18 A$ and 19B). Within lamina 6 itself, sparse, widespreading, and coarse fiber projections extend as far as $2.5 \mathrm{~mm}$ to each side of the injection. Denser but finer projections also occur. These often spread asymmetrically (for up to $900 \mu \mathrm{m}$ ) to one side, and sometimes they appear in clusters (Fig.
20 , arrow). These wide ranging lateral projections are difficult to demonstrate in the retrograde direction.

\section{Discussion}

From these results, as well as previous studies, it is clear that cortical circuits pass information radially, between separate functional layers. In this and the preceding paper, we have exploited patterns of axonal connectivity to distinguish 12 such layers in striate 


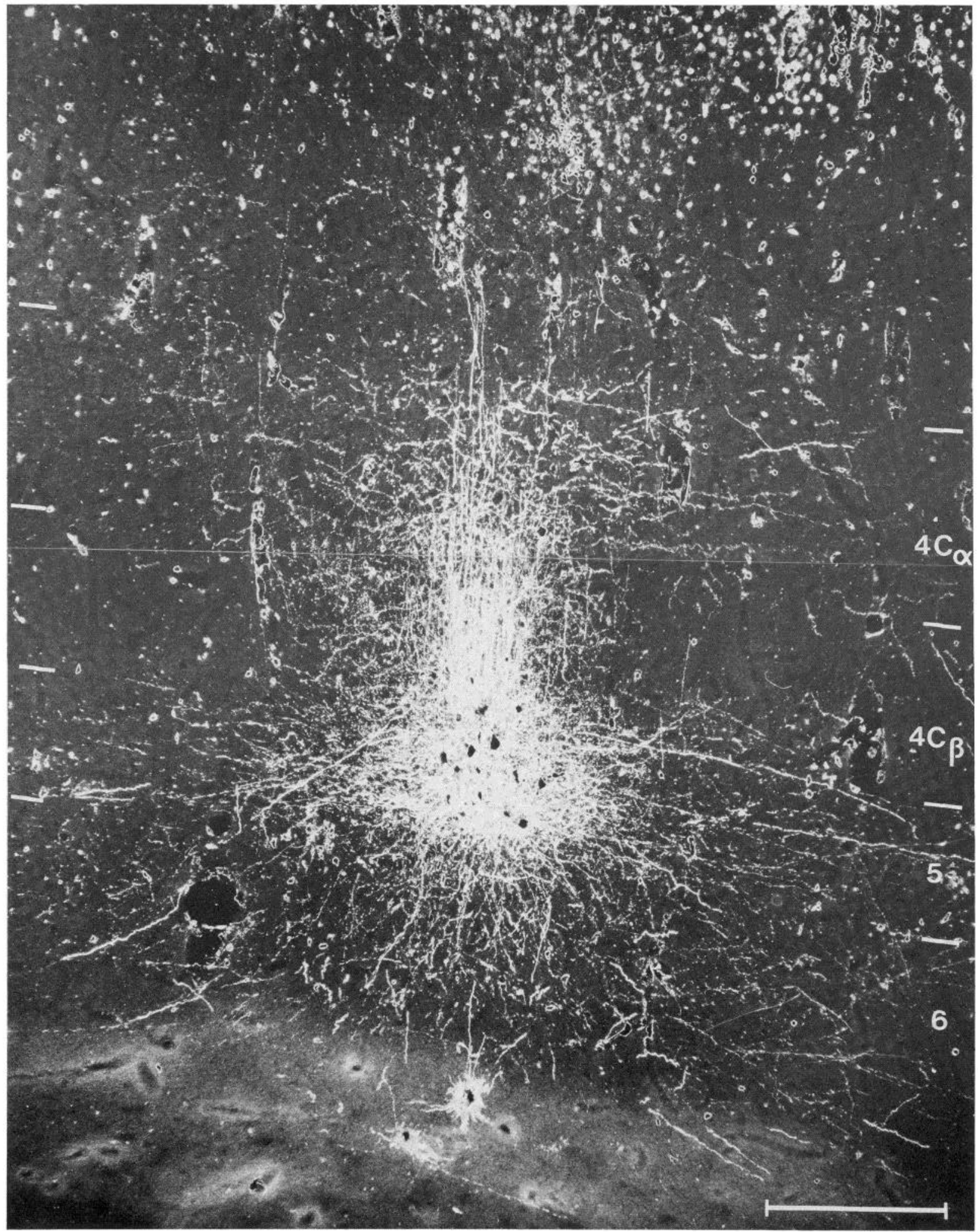

Figure 14. Following an injection into lamina 5, this darkfield photomicrograph reveals fiber labeling in laminae $4 \mathrm{C} \alpha$, $4 \mathrm{C} \beta, 5$, and 6 . Due to the oblique angle of section, more superficial patterns of fiber labeling are not observed in this section but are evident in the photomicrograph of a nearby section which appears in Figure 15. Scale bar $=200 \mu \mathrm{m}$.

cortex-1, 2/3A, 3B, 4A, 4B, upper and lower $4 \mathrm{C} \alpha$, upper and lower $4 \mathrm{C} \beta, 5 \mathrm{~A}, 5 \mathrm{~B}$, and 6 -and suggest that each may represent a separate, discrete step (whether parallel or serial) in the processing of visual information.

New projections. Among the new findings of this study are: (1) the nature of the projection from lamina $4 B$ to lamina $2 / 3 A ;(2)$ the presence of a feedback projection, from 2/3A back onto $4 \mathrm{~B}$; and (3) the presence of a projection from $4 B$ to lamina 5. Even though previous Golgi work (Lund and Boothe, 1975) demonstrated a projection from lamina $4 \mathrm{~B}$ to $2 / 3 \mathrm{~A}$, we were surprised in the present 


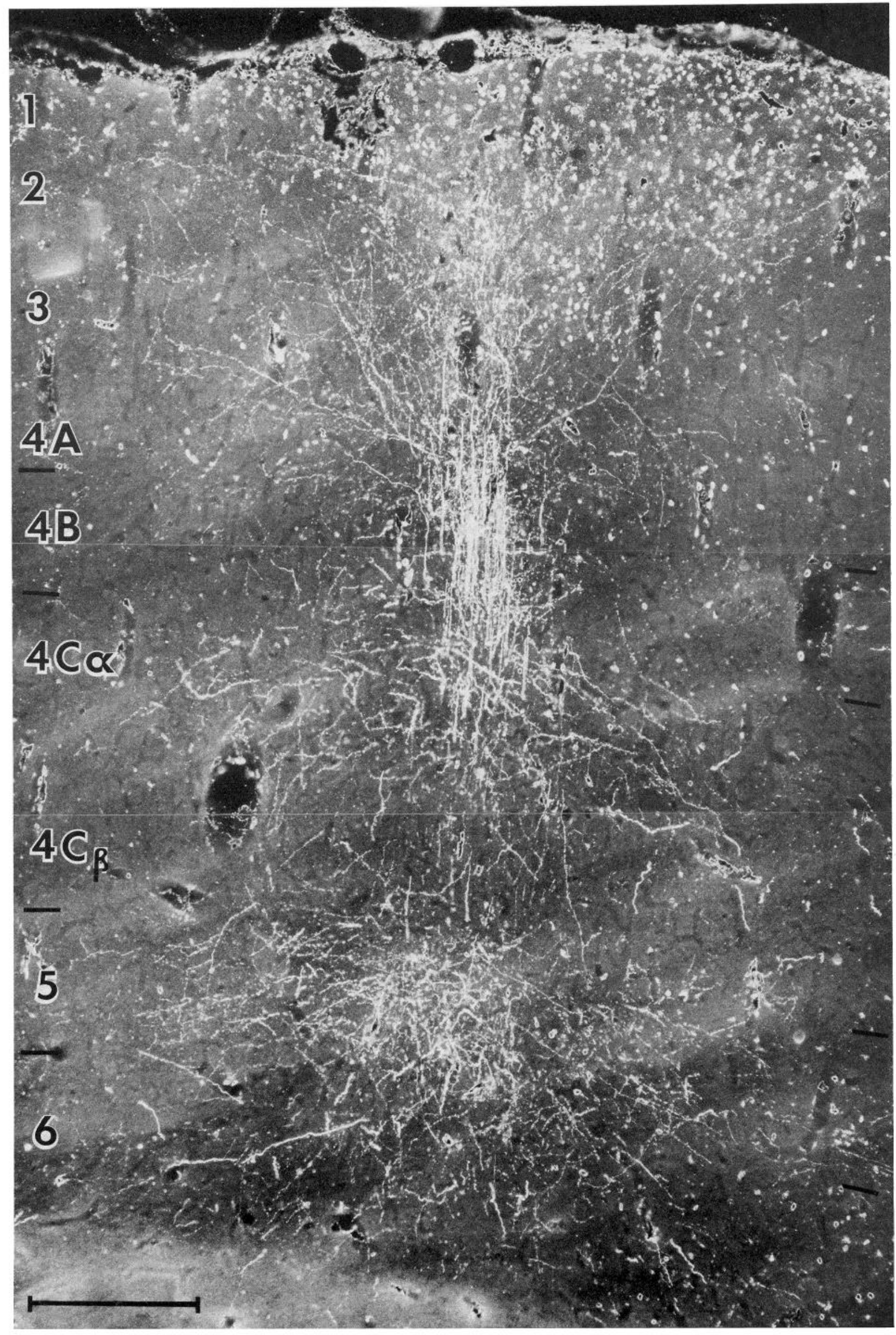




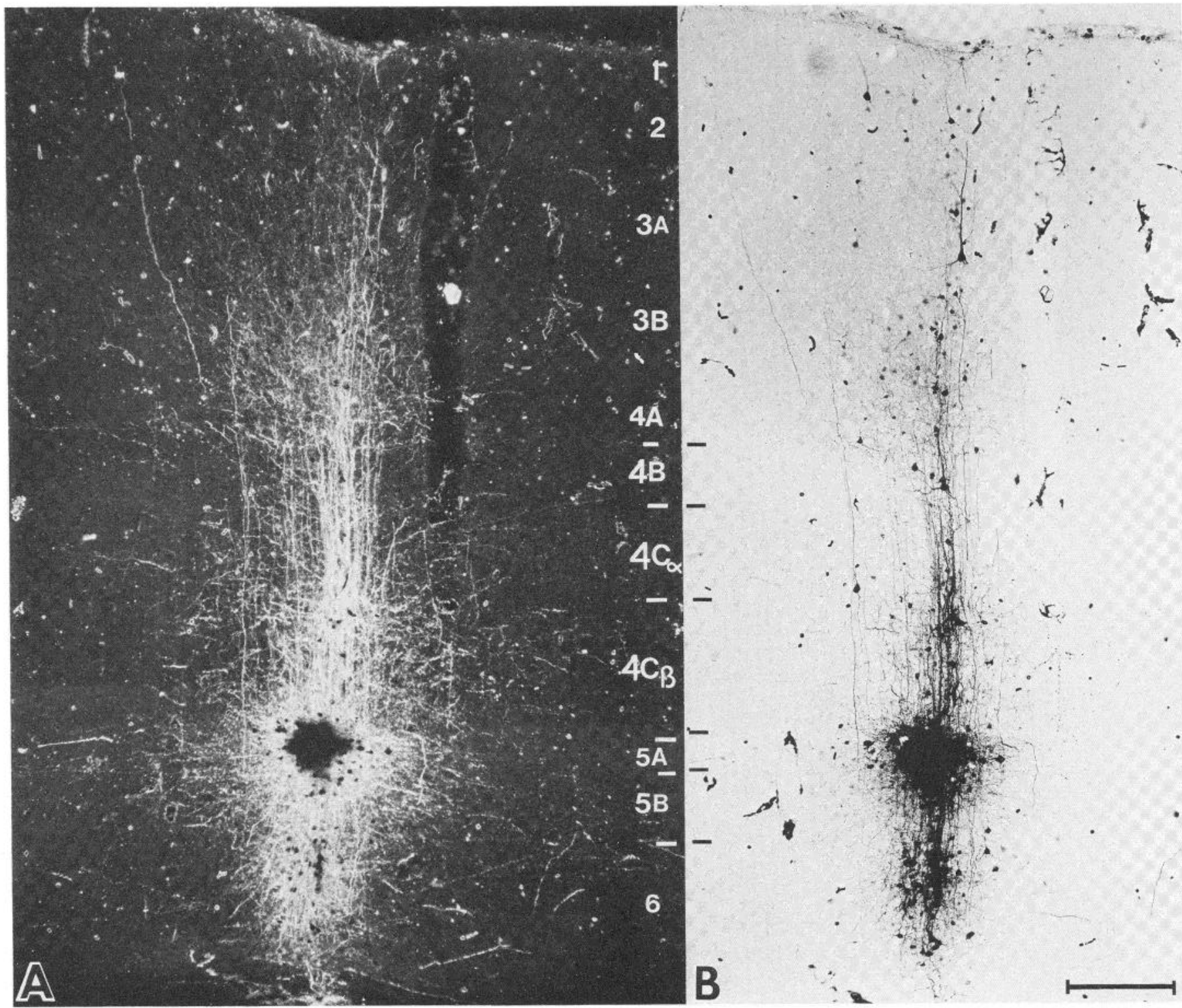

Figure 16. Darkfield $(A)$ and brightfield $(B)$ photomicrographs of an injection that is centered on lamina $5 \mathrm{~A}$, with some encroachment, onto laminae $4 \mathrm{C} \beta$ and $5 B$. Notice that the arbors labeled in laminae $4 C$ and $2 / 3$ spread less widely than they do following an injection into $5 B$, and those to $3 B / 4 A$ are the most prominent of the superficial projections (see, for example, Figs. 14 and 15). In the brightfield photomicrograph of $B$, retrogradely labeled somata are apparent in laminae 6, mid-4C, 4B, 4A, and 2/3; they are especially prominent in lamina 3B. Scale bar $=200 \mu \mathrm{m}$.

material by the intensity of this projection as well as by its focused nature. The neurons of lamina $4 B$ evidently make a marked and highly ordered contribution to the activities of neurons in lamina 2/ $3 \mathrm{~A}$. The reciprocal, feedback projection from $2 / 3 \mathrm{~A}$ to $4 \mathrm{~B}$ is not particularly dense (compared, for example, to that from $2 / 3 A$ onto $5)$, but it is discrete and relatively well confined to the region immediately under the injection site. Although our material also shows retrogradely labeled somata in this region-an indication that we may have labeled recurrent 4B collaterals-a direct input from $2 / 3 A$ seems to be confirmed by the retrogradely labeled neurons in $2 / 3 \mathrm{~A}$ that appear following injections into $4 \mathrm{~B}$. This interpretation is also supported by the existence of a comparable projection in the striate cortex of squirrel monkeys (Fitzpatrick et al., 1983).

The projection from lamina $4 \mathrm{~B}$ to lamina $5 \mathrm{~B}$ suggests a routethrough $4 \mathrm{C} \alpha$ and $4 \mathrm{~B}$ - for magnocellular input to the cells in lamina $5 B$. Since $5 B$ contains most of the neurons in striate cortex that project to the superior colliculus, this input fits with the observations of Schiller et al. (1979), who found that they could interrupt cortical input to the superior colliculus by locally anesthetizing magnocellular LGN laminae. We find it intriguing, however, that information derived from cells in the parvocellular LGN laminae, which is available to lamina 5B through a sequence of projections that includes laminae

Figure 15. This photomicrograph shows patterns of superficial fiber labeling following an injection into lamina 5 . Note that the fibers observed in laminae $4 \mathrm{~A}$ and $4 \mathrm{~B}$ are reasonably well aligned along the projection axis. Lamina $4 \mathrm{~B}$ contains few spreading fibers and does not appear to be a prominent target of lamina 5 projections. Clearly spreading arbors are observed in lamina 2/3A, however. From ongoing studies (J. S. Lund, unpublished observations) we do know, however, that smooth dendritic neurons in 5A contribute axon terminals to 4B. This could explain cell labeling in 5A following HRP injections into 4B (see Fig. 11). Scale bar $=200 \mu \mathrm{m}$. 

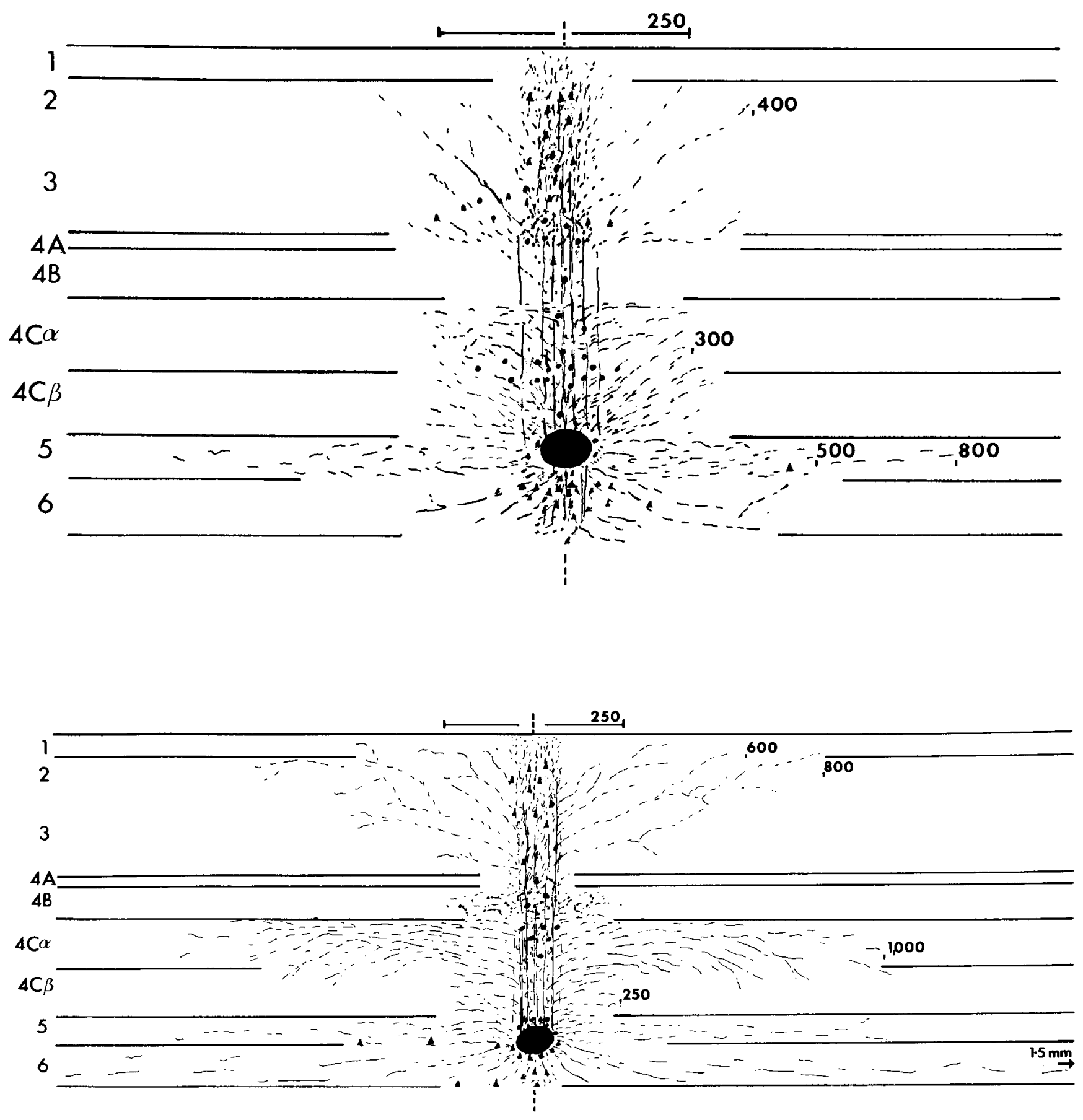

B

Figure 17. Summary diagrams of the cell and fiber labeling that are seen following HRP injections into laminae $5 A(A)$ and $5 B(B)$.

$4 \mathrm{C} \beta, 3 \mathrm{~B} / 4 \mathrm{~A}$, and $2 / 3 \mathrm{~A}$, cannot by itself drive the efferent neurons of lamina $5 \mathrm{~B}$. If cortical contributions to the receptive fields of cells in the superior colliculus are dominated by striate cortex (and not, for example, by the middle temporal visual area (MT), it would appear that the pyramidal cells of lamina 5B combine their parvoand magnocellular inputs in a fashion more complicated than simple summation.

Striate "circuits." There are several sets of projections in macaque striate cortex that appear directed to particular sets of efferent neurons. These are: (1) the projections that support output to V2, (2) those that provide output to MT (the movement-sensitive part of the superior temporal sulcus (Zeki, 1974; Maunsell and Van Essen, 1983), (3) those that provide information to the superior colliculus and other brainstem nuclei concerned with the control of eye movements, (4) those that provide feedback to the LGN as well as to various intermediate cortical laminae, and (5) those that do not leave striate cortex but which nevertheless affect the coordinated activities of other cortical circuits.

The first of these "circuits," which operates between the zone of LGN afferents and the cells which send efferents to V2 of extrastriate cortex, begins with parallel projections-one from lamina $4 \mathrm{C} \alpha$ to $4 \mathrm{~B}$, and another from $4 \mathrm{C} \beta$ to $3 \mathrm{~B} / 4 \mathrm{~A}$. Axons from cells in the two target laminae, $4 \mathrm{~B}$ and $3 \mathrm{~B} / 4 \mathrm{~A}$, then converge onto cells in lamina 2/ $3 \mathrm{~A}$, many of which project to $\mathrm{V} 2$. Accordingly, this route represents a major avenue in the flow of information between thalamus and extrastriate cortex. 

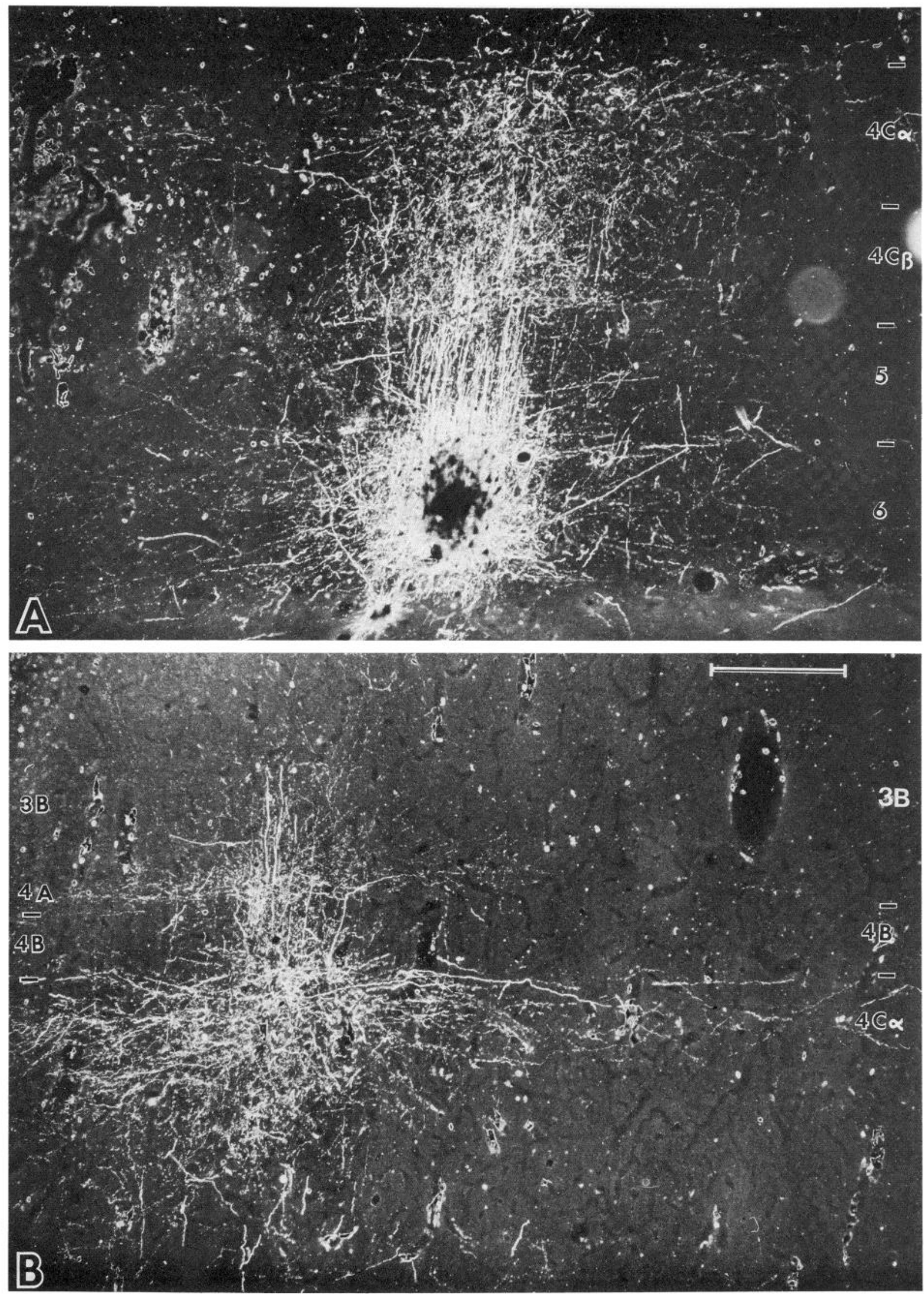

Figure 18. These darkfield photomicrographs show the pattern of fiber labeling that is observed after injections of HRP into lamina 6 . Due to the oblique angle of these sections, relative to the radial projection axis, the patterns of fiber labeling that are observed in laminae 6,5 , and $4 C \beta$ are most apparent in $A$, whereas the patterns of labeling for laminae $4 \mathrm{C} \alpha, 4 \mathrm{~B}$, and $3 \mathrm{~B}$ are most apparent in the section shown in $B$. The details of projections to laminae 1 and $2 / 3 \mathrm{~A}$ are best illustrated in Figure 19. Scale bar $=200 \mu \mathrm{m}$. 


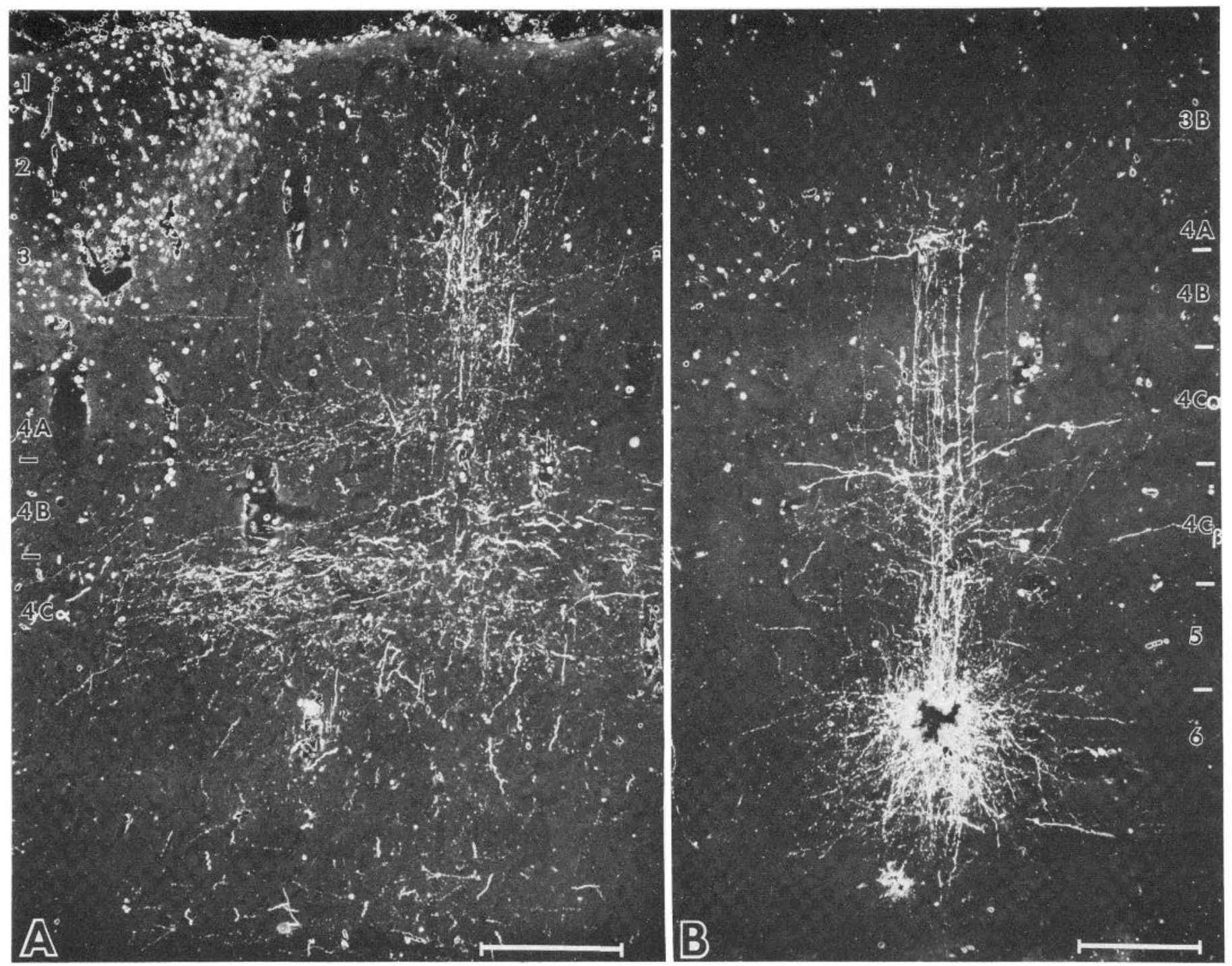

Figure 19. In this darkfield photomicrograph $(A)$, a microinjection of HRP into lamina 6 (see $B$ ) is observed to produce fiber labeling in laminae $4 \mathrm{C} \alpha$, $4 \mathrm{~B}$, $4 \mathrm{~A}, 3,2$, and 1 . Due to the oblique angle of section, the fiber projections to deeper layers are not apparent. From this photograph it is clear that the axons of lamina 6 neurons spread farther laterally in $4 C$ than they do in $4 A$, and that there is much less spread in the projections to lamina 3B (see also Fig. 18B). Nevertheless it is possible to observe a few widely spreading fibers in the superficial laminae. Lamina $4 \mathrm{~B}$ appears to get little or no input. In $B$ one sees the fiber and dendritic labeling that are produced by a small HRP injection in lamina 6 . The contributions of layer 6 axons and dendrites to laminae $4 \mathrm{C}$ and $3 \mathrm{~B} /$ $4 \mathrm{~A}$ are clearly evident. Scale is $200 \mu \mathrm{m}$.

A second "circuit" is suggested by projections that ultimately deliver information to MT. Most of the striate efference to MT arises from pyramidal and spiny stellate cells in lamina 4B (Lund et al., 1975; Spatz, 1975; Tigges et al., 1981; Maunsell and Van Essen, 1983). Although both of these cell types receive input from lamina $4 \mathrm{C} \alpha$, pyramidal cells receive layer $2 / 3 \mathrm{~A}$ input as well, via their apical dendrites. In addition to 4B neurons, there also appear to be a few pyramidal cells in layer 6 that project to MT (Spatz, 1975). The precise inputs to these cells are not known but could include information from virtually any overlying layer.

A third. "circuit" can be identified with the connections of neurons in lamina $5 \mathrm{~B}$ that project to the superior colliculus as well as to other brainstem nuclei. Intrinsic inputs to 5B derive mostly from cells in layers $4 \mathrm{~B}$ and $2 / 3 \mathrm{~A}$ which, as noted above, also provide most of the striate input to V2. Input to 5B pyramidal cells also occurs over their apical dendrites, which arborize in lamina 2/3a.

A fourth "circuit" can be discerned in the feedback loops of lamina 6. As first noted by Lund (1973), it is difficult to establish a major route for input to this layer since it seems to receive a light one from all of the others and even from the LGN. In the present material, however, layer 6 appears to receive much of its input from lamina 5. Such an input is apparent anatomically in the cat (Gilbert and Wiesel, 1979) and is consistent with physiological observations of large receptive field sizes for neurons in both laminae 5 and 6 of the macaque monkey (Dow, 1974; Hubel and Wiesel, 1977; G. G. Blasdel and D. Fitzpatrick, unpublished observations). As shown in the preceding paper, lamina 6 projects heavily onto lamina $4 \mathrm{C}$ and provides a sizeable input to lamina 4A as well. McGuire et al. (1984) reported recently that the recurrent collaterals of cat layer 6 pyramidal neurons preferentially contact the dendrites of aspinous neurons in lamina 4. This finding and those of the current study support the idea that layer 6 neurons provide a modulatory feedback to laminae $4 \mathrm{C}$ and $4 \mathrm{~A}$

The neurons of lamina $5 A$, which receive a relatively focused input from cells in most overlying laminae, are involved with yet a fifth and fundamentally different type of "circuit." Unlike 5B neurons, which project subcortically, 5A cells have not been shown to project outside of striate cortex; and since most of their output goes back to laminae supplying them with input, these neurons appear to act more as an auxillary network-one that functions together with cells 


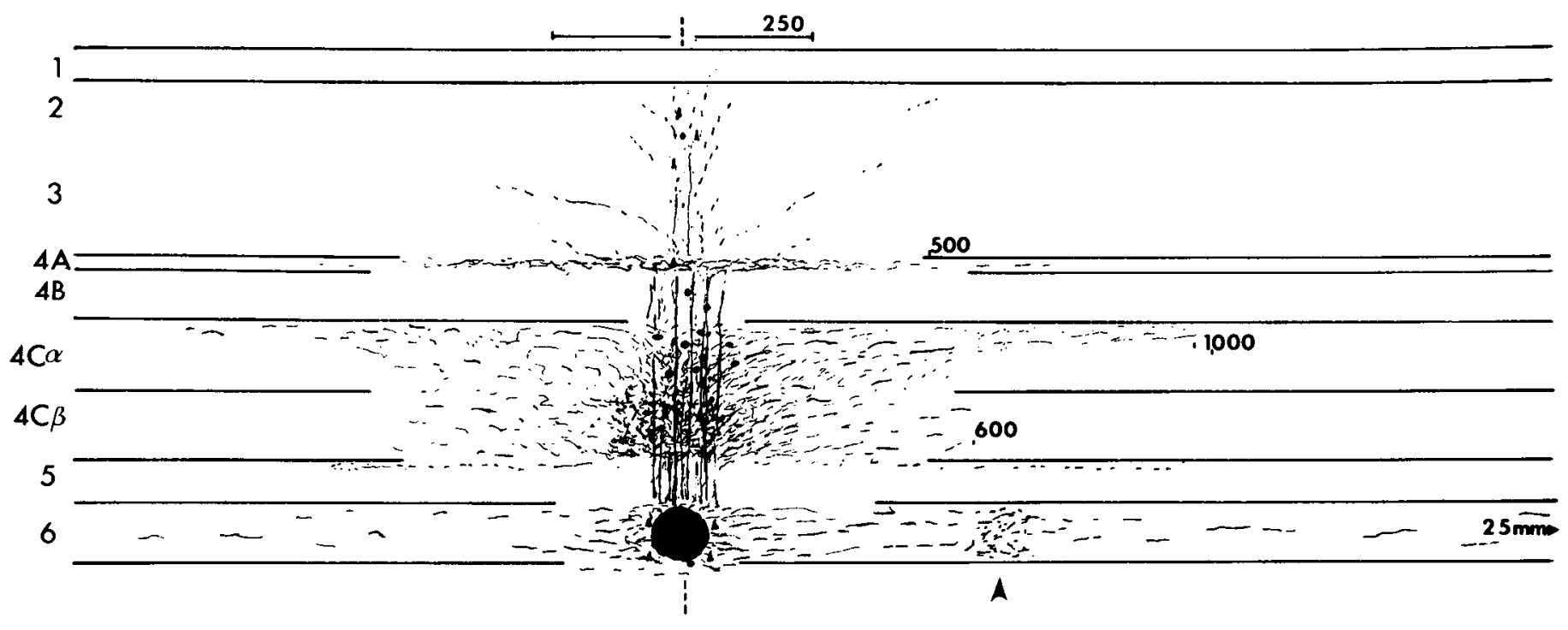

Figure 20. Summary diagram of the cell and fiber labeling that are observed after HRP injections into lamina 6 . The arrowhead marks the position of one terminal cluster that appears to one side of the injection site. The greatest observed spreads (away from the radial axis) of some projections are indicated in micrometers.

in other, more superficial laminae-than as a major conduit in the transference of visual information.

Divergence of the $4 B$ and $3 B / 4 A$ projections onto lamina $2 / 3 A$. In the preceding paper we examined projections from laminae $4 \mathrm{C} \alpha$ to $4 \mathrm{~B}$, and from $4 \mathrm{C} \beta$ to $3 \mathrm{~B} / 4 \mathrm{~A}$. We also found that there are few if any direct projections from lamina $4 \mathrm{C}$ to $2 / 3 \mathrm{~A}$. In the present study we have extended these findings to show that laminae $4 B$ and $3 B /$ $4 A$ both contain neurons that project strongly to $2 / 3 \mathrm{~A}$. Thcsc projections do not distribute in the same manner, however, since the axons of $3 B / 4 A$ neurons spread much more widely than those of $4 \mathrm{~B}$ neurons. The difference is most apparent in the distribution of retrograde label following an injection into $2 / 3 \mathrm{~A}$ (see Fig. 6); labeled somata cxtend farther laterally in lamina $3 \mathrm{~B} / 4 \mathrm{~A}$ than in $4 \mathrm{~B}$, and the difference appears with orthograde transport as well (Figs. $8 A$ and 1A).

One explanation for this difference is that $3 \mathrm{~B} / 4 \mathrm{~A}$ axons, which form a part of the parvocellular stream (that is, which carry information derived from parvocellular LGN laminae), simply match an earlier divergence in the magnocellular stream. This divergence occurs at both the input and the output of lamina $4 \mathrm{C} \alpha$ and appears to go unmatched by the parvocellular stream. On the input side, individual magnocellular afferents cover 6 times as much area as individual parvocellular afferents (Blasdel and Lund, 1983), and on the output end, efferents from lamina $4 \mathrm{C} \alpha$ to $4 \mathrm{~B}$ spread much more widely than efferents from $4 \mathrm{C} \beta$ to $3 \mathrm{~B} / 4 \mathrm{~A}$ (Fitzpatrick et al., 1985). In order tor these two streams to line up again, topographically, one might expect that a compensating parvocellular divergence is required; and this, apparently, occurs in the projection from 3B/4A to ?/3A.

An alternative (and not necessarily contradictory) explanation involves the hypothesis that connections between laminae having dissimilar maps are likely to show greater dispersion. According to this explanation, which is detailed later on, laminae $4 \mathrm{~B}$ and $2 / 3 \mathrm{~A}$, both of which contain binocular neurons and maps for orientation, are likely to be linked with precise connections since their maps are congruent. Lamina 4A, in contrast, which appears to lack binocular neurons as well as a map for orientation (Blasdel and Fitzpatrick, 1984), will probably not be congruent with lamina $2 / 3 \mathrm{~A}$, and, accordingly, connections between the two might need to diverge.

Lamina 5 . The projection from lamina $2 / 3 \mathrm{~A}$ to lamina 5 appears in a wide variety of species and characterizes several cortical areas (Nauta et al., 1973; Lund and Boothe, 1975). In macaque striate cortex it appears that this projection arises at least in part from the collaterals of axons that project to extrastriate cortex. Although an injection of HRP into lamina $2 / 3 \mathrm{~A}$ generally produces a dense cluster of terminals in lamina 5 , it also produces a field of more lightly labeled terminals that extends laterally (in lamina 5) for much larger distances (up to $900 \mu \mathrm{m}$ ). Several investigators, who uscd larger injections of HRP (Rockland and Lund, 1983; Livingstone and Hubel, $1984 a, b)$, have reported that these wider spreading patches appear laterally periodic and that they underlie patches of label in lamina 2/ $3 \mathrm{~A}$ that are produced by the same injection. It remains to be worked out, however, whether the layer 5 patches derive from neurons in $2 /$ $3 \mathrm{~A}$ that send collaterals both to the injection site and to lamina 5 , or from neurons at the injection site that project, in a widespread patchy fashion, to both lamina 2/3A and lamina 5.

Pyramidal cell input. Pyramidal cells receive two prominent sources of input: one applied to the apical dendrite, and another on the basal dendrites. A cell in lamina $5 \mathrm{~B}$, for example, that receives input onto its apical dendrite in lamina $2 / 3 \mathrm{~A}$, also receives input onto its basal dendrites from $2 / 3 \mathrm{~A}$ neurons that project down to lamina 5. What is the significance of this separation? The most obvious difference for pyramidal cells in lamina $5 B$ is that the basal dendrites receive input only from the axons of cells in lamina $2 / 3 A$, whereas the apical dendrite may be contacted by the inputs to $2 / 3 \mathrm{~A}$ neurons as well. Accordingly, these cells are able to compare the outputs of 2/3A neurons with their inputs. Although there are many ways in which a comparison such as this might be exploited, one obvious possibility would be for $5 \mathrm{~B}$ pyramidal cells to derive an error signal from discrepancies between information reaching 2/3A neurons and information that they pass on to $\mathrm{V} 2$. Given a lag, the difference between these two signals should produce something like a first derivative: $d / / d t$ (where / represents information passed to V2). This error signal could then be sent to appropriate brainstem nuclei that are concerned with (for example) the control of smooth pursuit eye movements. The known responses of tectal projecting cells, in layer 5 of the cat, to small jiggling spots of light (Palmer and Rosenquist, 1974), may reflect such an operation. Comparable operations are conceivable for pyramidal cells in other layers as well. The important point seems to be that these cells are capable of making interlaminar comparisons at a given point in cortical space.

Relations between interlaminar projections and laminar mapping. In. studying the anatomical relations between input and output sublaminae of macaque striate cortex, it is important to consider transformations that are known to occur physiologically. On the input side we know that most cells receiving thalamic input lack orientation selectivity and are monocular. This conclusion obtains for cells in laminae $4 \mathrm{C} \beta, 4 \mathrm{C} \alpha, 4 \mathrm{~A}$, and the patchy input zones in $2 / 3 \mathrm{~A}$, although there may be more orientation selectivity in lamina $4 \mathrm{C} \alpha$ than sus- 
pected initially (Hubel and Wiesel, 1968, 1977; Bullier and Henry, 1980; Blasdel and Fitzpatrick, 1984; Livingstone and Hubel, 1984a; Parker and Hawken, 1984). In addition, 4C cells have the smallest and most retinotopically mapped receptive fields in striate cortex.

On the efferent side, neurons have larger receptive fields, and they tend to respond binocularly in an orientation-dependent fashion. Moreover, the detailed and precise retinotopic map, so evident for cells in lamina 4C (Hubel et al., 1974; Hubel and Wiesel, 1974; Blasdel and Fitzpatrick, 1984), fades considerably in the output laminae and appears to be replaced by an equally precise one for orientation. Since the new orientation map squeezes into an existing retinotopic one, the latter must be distorted (Hubel and Wiesel, 1974); and an exact correspondence with maps that lack this distortion is not possible. Accordingly, information about a point in visual space, that passes from a retinotopically mapped lamina to an orientation-mapped one, must make a lateral jump; and it seems likely that jumps such as these will be reflected anatomically in the projections of axons between them.

With these constraints in mind, it is interesting to consider the patterns of connectivity that we have uncovered. At one extreme we have precise projections such as the point-to-point one between laminae $4 \mathrm{C} \beta$ and $4 \mathrm{~A}$. On the basis of the foregoing discussion, these laminae would appear to have congruent maps; and, indeed, the available (although sparse) physiological evidence suggests a non-oriented, retinotopic, and monocular map for the cells in lamina $4 \mathrm{~A}$ as well as for the cells in $4 \mathrm{C} \beta$ (Blasdel and Fitzpatrick, 1984).

At the other extreme, we have the highly divergent projections that appear to link lamina $4 \mathrm{C}$ with laminae containing orientationally selective cells-for example, the projections from $4 \mathrm{C} \beta$ to $3 \mathrm{~B}$, or from $4 \mathrm{C} \alpha$ to $4 \mathrm{~B}$. The divergence in these anatomical links fits with the reordering that one might expect for links between dissimilar maps. Interestingly, the projections between two orientation-mapped laminae, for example, between $4 B$ and $2 / 3 A$, can also be quite specific, and just as focused as those between $4 \mathrm{C} \beta$ and $4 \mathrm{~A}$. It seems reasonable therefore to suggest that connections between laminae with congruent maps are characterized by point-to-point projections, whereas connections between laminae having dissimilar maps are characterized by projections that spread.

As discussed previously (Rockland and Lund, 1983; Livingstone and Hubel, 1984a, b), some intralaminar projections-in particular those in laminae $2 / 3 \mathrm{~A}$ and $4 \mathrm{~B}$ - -appear patchy and periodic. Projections between laminae may also be periodic, however, one example being that between $2 / 3 \mathrm{~A}$ and 5 . Since laterally periodic projections manage simultaneously to be focused and spreading, they may engage in some type of receptive field enlargement. They may, for example, account for the well known increase in receptive field size that accompanies each successive step in the visual pathway, (Hubel and Wiesel, 1962, 1968, 1977; Van Essen et al., 1984). Before the emergence of orientation selectivity, such an enlargement can be accomplished rather simply by pooling reccptive ficlds. After the appearance of an ordered map for orientation, however, the circuitry becomes more complex. For the orientation-specific neurons in one lamina to support larger, orientation-specific, receptive fields in another (through the lateral addition of excitatory or inhibitory flanks), connections must: (1) ramify perpendicular to the radial projection axis; (2) make contacts where the orientational preference is appropriate; and (3) skip regions where the orientational preference is inappropriate. Accordingly, laminae that have similar maps for orientation, but neurons with different receptive field sizes, might well be connected by axons that spread in a laterally periodic fashion. In the case of the periodic projections from lamina $2 / 3 \mathrm{~A}$ to $5 \mathrm{~B}$, and from lamina $4 \mathrm{~B}$ to $5 \mathrm{~B}$, this relation appears to hold. Physiological studies have shown (1) that these laminae are characterized by orientationally selective cells (excluding the "blob" cells of lamina 3 ), and (2) that cells in lamina 5 have larger receptive fields than cells in either 2/3A or 4B; (Hubel and Wiesel, 1977; Blasdel and Fitzpatrick, 1984; Dow et al., 1981).

\section{References}

Blasdel, G. G., and D. Fitzpatrick (1984) Physiological organization of layer 4 in macaque striate cortex. J. Neurosci. 4: 880-895.

Blasdel, G. G., and J. S. Lund (1983) Termination of afferent axons in macaque striate cortex. J. Neurosci. 3: 1389-1413.

Blasdel, G. G., D. Fitzpatrick, and J. S. Lund (1983) Organization and intracortical connectivity of layer 4 in macaqule striate cortex. Soc. Neurosci. Abstr. 9: 476 .

Bullier, J., and G. H. Henry (1980) Ordinal position of afferent input of neurons in monkey striate cortex. J. Comp. Neurol. 193: 913-936.

De Valois, R. L., D. G. Albrecht, and L. G. Thorell (1982) Spatial frequency selectivity of cells in macaque visual cortex. Vis. Res. 22: 545-559.

Dow, B. M. (1974) Functional classes of cells and their laminar distribution in monkey visual cortex. J. Neurophysiol. 37: 927-946.

Dow, B. M., A. Z. Synder, R. G. Vautin, and R. Bauer (1981) Magnification factor and receptive field size in foveal striate cortex of the monkey. Exp. Brain Res. 44: 213-228.

Fitzpatrick, D., K. Itoh, and I. T. Diamond (1983) The laminar organization of the lateral geniculate body and the striate cortex in the squirrel monkey (Saimiri sciureus). J. Neurosci. 3: 673-702.

Fitzpatrick, D., J. S. Lund, and G. G. Blasdel (1985). Intrinsic connections of macaque striate cortex: Afferent and efferent connections of lamina $4 \mathrm{C}$. J. Neurosci. 5: 3329-3349

Gilbert, C. D., and T. N. Wiesel (1979) Morphology and intracortical projections of functionally characterized neurones in the cat visual cortex. Native 280: $120-125$

I lendrickson, A. E., J. R. Wilson, and M. P. Ogren (1978) The neuroanatomical organizations of pathways between dorsal lateral geniculate nucleus and visual cortex in Old and New World primates. J. Comp. Neurol. 182: 123136

Hubel, D. H., and T. N. Wiesel (1962) Receptive fields, binocular interaction and functional architecture of monkey striate cortex. J. Physiol. (Lond.) 195: $106-154$.

Hubel, D. H., and T. N. Wiesel (1968) Receptive fields and functional architecture of monkey striate cortex. J. Physiol. (Lond.) 195: 215-243.

Hubel, D. H., and T. N. Wiesel (1972) Laminar and columnar distribution of geniculo-cortical fibers in the macaque monkey. J. Comp. Neurol. 146: $421-450$.

Hubel, D. H., and T. N. Wiesel (1974) Uniformity of monkey striate cortex: A parallel relationship between field size, scatter and magnification factor. $\mathrm{J}$. Comp. Neurol. 158: 295-306.

Hubel, D. H., and T. N. Wiesel (1977) Functional architecture of macaque monkey visual cortex. Proc. R. Soc. Lond. (Biol.) 198: 1-59.

Hubel, D. H., T. N. Wiesel, and S. LeVay (1974) Visual field of representation in layer IVC of monkey striate cortex. In Society for Neuroscience Program and Abstracts, 1974, p. 264, Society for Neuroscience, Bethesda, MD.

Livingstone, M. S., and D. H. Hubel (1984a) Anatomy and physiology of a color system in the primate visual cortex. J. Neurosci. 4: 309-356.

Livingstone, M. S., and D. H. Hubel (1984b) Specificity of intrinsic connections in primate primary visual cortex. J. Neurosci. 4: 2830-2835.

Lund, J. S. (1973) Organization of neurons in the visual cortex, area 17, of the monkey (Macaca mulatta). J. Comp. Neurol. 147: 455-496.

Lund, J. S. (1980) Intrinsic organization of the primate visual cortex, area 17 as seen in Golgi preparations. In The Organization of the Cerebral Cortex. Proceedings of a Neuroscience Research Program Colloquium, F. O. Schmitt, F. G. Worden, G. Adelman, and S. G. Dennis, eds., pp. 97-121, MIT Press, Cambridge, MA.

Lund, J. S., and R. G. Boothe (1975) Interlaminar connections and pyramidal neuron organization in the visual cortex, area 17 , of the macaque monkey. J. Comp. Neurol. 159: 305-334.

Lund, J. S., R. D. Lund, A. E. Hendrickson, A. H. Bunt, and A. F. Fuchs (1975) The origin of efferent pathways from the primary visual cortex (area 17 ) of the macaque monkey as shown by retrograde transport of horseradish peroxidase. J. Comp. Neurol. 164: 287-304.

Lund, J. S., D. Fitzpatrick, and G. G. Blasdel (1983) Intrinsic connections of macaque striate cortex. Soc. Neurosci. Abstr. 9: 476

Maunsell, J. H. R., and D. C. Van Essen (1983) The connections of the middle temporal visual area (MT) and their relationship to a cortical hierarchy in the macaque monkcy. J. Neurosci. 3: 2563-2586.

McGuire, B. A., J. P. Hornung, C. D. Gilbert, and T. N. Wiesel (1984) Patterns of synaptic input to layer 4 of cat striate cortex. J. Neurosci. 4: $3021-$ 3033 .

Michael, C. R. (1978) Color vision mechanisms in monkey striate cortex: Dual-opponent cells with concentric receptive fields. J. Neurophysiol. 41: 
572-588.

Mitzdorf, U., and W. Singer (1979) Excitatory synaptic ensemble properties in the visual cortex of the macaque monkey: A current source density analysis of electrically evoked potentials. J. Comp. Neurol. 187: 71-84.

Movshon, J. A., I. D. Thompson, and D. J. Tolhurst (1978) Spatial and temporal contrast sensitivity of neurones in areas 17 and 18 of the cat's visual cortex. J. Physiol. 283: 101-120.

Nauta, H. J. W., A. B. Butler, and J. Jane (1973) Some observations on axonal degeneration resulting from superficial lesions of the cerebral cortex. J. Comp. Neurol. 150: 349-360.

Palmer, L. A., and A. C. Rosenquist (1974) Visual receptive fields of single striate cortical units projecting to the superior colliculus in the cat. Brain Res. 67: 27-42.

Parker, A. J., and M. J. Hawken (1984) Contrast sensitivity and orientation selectivity in lamina IV of the striate cortex of old-world monkeys. Exp. Brain Res. 54: 367-373.

Pollen, D. A., and S. F. Ronner (1983) Visual cortical neurones as localized spatial frequency filters. IEEE Trans. Syst. Man. Cybern. SMC-13: 907916.

Rockland, K. S., and J. S. Lund (1983) Intrinsic laminar lattice connections in primate visual cortex. J. Comp. Neurol. 216: 303-318.

Schiller, P. H., B. L. Finlay, and S. F. Volman (1976) Quantitative studies of single cell properties in monkey striate cortex. I. Spatiotemporal organization of receptive fields. J. Neurophysiol. 39: 1288-1319.

Schiller, P. H., J. G. Malpeli, and S. J. Schein (1979) Composition of geniculostriate input to superior colliculus of the rhesus monkey. J. Neurophysiol. 42: 1124-1132.

Spatz, W. B. (1975) An efferent connection of the solitary cells of Meynert. A study with horseradish peroxidase in the mamoset Callithrix. Brain Res. 92: 450-455.

Tigges, J., M. Tigges, S. Anschel, N. A. Cross, W. D. Letbetter, and R. L. McBride (1981) Areal and laminar distribution of neurons interconnecting the central visual cortical areas $17,18,19$ and MT in squirrel monkey (Saimiri). J. Comp. Neurol. 202: 539-560.

Van Essen, D. C., W. T. Newsome, and J. H. R. Maunsell (1984) The visual cortex representation in striate cortex of the macaque monkey: Asymmetries, anisotropies and individual variability. Vision Res. 24R: 429-448.

Zeki, S. M. (1974) Functional organisation of a visual area in the posterior bank of the superior temporal sulcus of the monkey. J. Physiol. (Lond.) 236: 549-573. 